New remains of Lophiaspis maurettei (Mammalia, Perissodactyla) from the early Eocene of France and the implications for the origin of the Lophiodontidae.

QUENTIN VAUTRIN, $*{ }^{1}{ }^{\text {RODOLPHE TABUCE, }}{ }^{1}$ FABRICE LIHOREAU,${ }^{1}$ CONSTANCE BRONNERT, ${ }^{2}$ EMMANUEL GHEERBRANT, ${ }^{2}$ MARC GODINOT, ${ }^{3}$ GREGOIRE METAIS, ${ }^{2}$ JOHAN YANS, ${ }^{4}$ YVES DUTOUR, ${ }^{5}$ NICOLAS VIALLE,${ }^{5}$ PHILIP JEAN,${ }^{6}$ and GUILLAUME

\title{
BILLET $^{2}$
}

${ }^{1}$ Institut des Sciences de l'Evolution de Montpellier, Université Montpellier, CNRS, IRD, EPHE Cc 064; place Eugène Bataillon, 34095 Montpellier Cedex 5, France ; quentin.vautrin@umontpellier.fr ; rodolphe.tabuce@umontpellier.fr ; fabrice.lihoreau@umontpellier.fr ;

${ }^{2}$ Centre de Recherche en Paléontologie - Paris (CR2P, UMR7207), Sorbonne Université, Muséum national d'Histoire naturelle, CNRS, 8 rue Buffon, CP38, F-75005, Paris, France ; constance.bronnert@mnhn.fr; emmanuel.gheerbrant@mnhn.fr ; gregoire.metais@mnhn.fr; guillaume.billet@mnhn.fr ;

${ }^{3}$ Ecole Pratique des Hautes Etudes, PSL, UMR 7207 CR2P, Paris, France ; marc.godinot@mnhn.fr ; ${ }^{4}$ Département de Géologie - Institute of Life, Earth and Environment, Université de Namur, 61 rue de Bruxelles, 5000 Namur, Belgique ; johan.yans@unamur.be ;

${ }^{5}$ Muséum d'Histoire Naturelle d'Aix en Provence,7 allée des Robiniers, 13090 Aix en provence , France; viallen@mairie-aixenprovence.fr; dutoury@mairie-aixenprovence.fr ;

${ }^{6}$ CEREGE, Institut Pytheas, Aix-Marseille Université, 3 Place Victor Hugo, 13331 Marseille cedex 3, France ; jean.philip@univ-amu.fr ;

RH: VAUTRIN ET AL.-NEW REMAINS LOPHIASPIS.

1

* Corresponding author 
ABSTRACT_The Lophiodontidae are endemic perissodactyls from Europe that flourished during the Eocene. Despite their preponderance in the European fossil record, their exact origin and relationships within the perissodactyls remains unknown due to the rare and fragmentary material at the early Ypresian, the time of their earliest radiation.

Lophiaspis maurettei is the oldest and earliest diverging lophiodontid known to date but is unfortunately poorly known. We describe here the results of new excavations of the type locality of Palette. Important new material including complete skulls, mandibles, post-cranial elements and juvenile specimens lead us to revise Lophiaspis maurettei from Palette and other localities and to describe novel morphology for this species. According to an original phylogenetic analysis, based on a revised matrix of dental, cranio-mandibular and postcranial characters, Ls. maurettei is an early diverging lophiodontid morphologically close to Protomoropus and Paleomoropus, two basal chalicotheres, respectively known from Asia and North America. Our resulting topology does not support the previously proposed inclusion of the lophiodontids within the Ceratomorpha and supports a position within the suborder Ancylopoda, close to some Eomoropidae representatives. These results imply that Ls. maurettei was restricted to Southern Europe during the early Eocene, which would be compatible with an Asian origin for lophiodontids in accordance with the evolutionary history of other perissodactyls and placental mammals.

\section{INTRODUCTION}

The oldest remains referred to the modern order Perissodactyla appears at the earliest Eocene alongside Artiodactyla and Primates (Gingerich, 2006). This date is close and only slightly younger than several molecular estimates for the initial divergence within crown Perissodactyla (e.g., Meredith et al., 2011; Foley et al., 2016). The fossil record shows that the order Perissodactyla rapidly radiated into several sub-orders and families and was then represented on all the holarctic continents (Radinsky, 1969; Hooker and Dashzeveg, 2003; Bai et al., 2018). In Western Europe, 
perissodactyls were represented during the early Eocene by several equoids from the localities of Abbey Wood, UK (Hooker, 2010), Silveirinha, Portugal (Estravis, 1992), Erquelinnes, Belgium (Quinet and Verlinden, 1970; Missiaen et al., 2013), and the French localities of Le Quesnoy (Bronnert et al., 2018a), Fordones (Marandat et al., 2012), Rians (Godinot, 1981) and Palette (Godinot et al., 1987). In addition two tapiromorphs are documented in Europe at that time: one Isectolophidae from Le Quesnoy (Bronnert et al., 2018b) and one Lophiodontidae at Palette (Depéret, 1910) and Silveirinha (Estravis, 1992).

The lophiodontids, which are endemic to Southern Europe during the early Eocene (Robinet et al., 2015), rapidly dispersed through all Western Europe and became the largest ungulates of the region until their extinction at the end of the middle Eocene. The latest lophiodontids are well known (Sudre, 1971), and although two lophiodontids from the Ypresian (early Eocene), Eolophiodon laboriense Robinet, Rémy, Laurent, Danilo, and Lihoreau 2015, and Lophiodon aff. eygalayense, were documented recently (Godinot et al., 2018; Vautrin et al., 2019), the remains of earliest diverging lophiodontids are scarce and often fragmentary. For this reason, the origin of lophiodontids, and their phylogenetic relationships with other perissodactyl families remain poorly known.

Lophiaspis maurettei Depéret 1910, is the earliest-known lophiodontid and was the largest mammal of Southern Europe during the early Ypresian. The hypodigm of Ls. maurettei includes only the holotype, a fragmentary palate bearing the right P2-M3 and the left P3-M2 from the locality of Palette (Depéret, 1910). Two other specimens from Palette, a palate and a mandible, have been figured by Repelin (1930) but have been lost since. Isolated teeth of Lophiaspis maurettei have also been reported from the Portuguese site of Silveirinha (close to the European Mammal Paleogene level MP7) and later in Mutigny (Paris Basin; MP8+9), and in les Salères (Spain; MP10) (Savage et al., 1966; Estravis, 1992; Checa Soler, 1997). Ls. maurettei is a key taxon, notably because of its early occurrence, for understanding the relationships between the lophiodontids and 
other perissodactyls. As such, Ls. maurettei has often been used in phylogenetic analysis (Hooker and Dashzeveg, 2004; Bai et al., 2010, 2018), although only one fragmentary specimen was available. Traditionally, the lophiodontids were long considered as tapiroids (Cuvier, 1822; Filhol, 1888). However, Radinsky (1964) considered Ls. maurettei as closely related to the chalicotheroid Paleomoropus jepseni Radinsky, 1964. The familial status of Lophiaspis has been uncertain since then. Lophiodontids have been successively assigned to Ceratomorpha or Ancylopoda in the latest phylogenetic analyses (Hooker and Dashzeveg, 2004; Holbrook, 2009), and the position of Lophiaspis within the lophiodontids has often been challenged (Hooker, 1989; Bai et al., 2010, 2018).

Recent excavations were conducted in the MP7 locality of Palette (2016-2018) and have yielded new remains of Ls. maurettei, among other taxa. Lophiaspis maurettei is now documented by nearly complete crania, a mandible, some juvenile specimens and post-cranial elements, and thus becomes one of the best documented ungulate mammals of the early Eocene of Europe. The description of the craniomandibular and dental anatomy allows us to review the status of $L s$ maurettei from Palette and from other localities, and to update its geographic distribution during the early Eocene. Furthermore, the description of these new remains greatly improves our knowledge of the morphology of basal lophiodontids, and it considerably completes the coding of morphological characters of this key taxon in a new phylogenetic analysis. Finally, we investigate the relationships between the lophiodontids and the other perissodactyls, providing new insights about their origins.

\section{AGE OF LOCALITIES AND MATERIALS}

Most of the new specimens here described come from the locality of Palette (Provence, Southern France) (Godinot et al., 1987); we also mention a specimen from the new locality of SaintPierre-des-Champs (Corbières, Southern France) (Fig. 1) and reassess a specimen from Silveirinha (Baixo Mondego, Portugal). A comment on the age of these three $\sim$ MP7 localities is required. 
Following the Southern Europe biochronological sequence proposed by Marandat et al. (2012), Silveirinha is the oldest locality from the early Eocene of Southern Europe, possibly close to the Dormaal MP7 reference-level (Belgium), which is correlated with the onset of the Paleocene Eocene Thermal Maximum (PETM or ETM1) and the nannoplankton zone NP9b, around $56 \mathrm{Ma}$ (Steurbaut et al., 2003; Smith et al., 2006). Palette is considered younger than Silveirinha (Marandat et al., 2012) and coeval with two other localities from Southern France, namely Fordones and Le Clot (Corbières area). Interestingly, these two mammalian faunas come from a thin continental level succession, which conformably overlies a very thick section of the marine "Early Ilerdian" (early Ypresian). This continental level corresponds to a brief regressive phase occurring during the “Middle Ilerdian”(Marandat et al., 2012). Based on chemostratigraphy, Yans et al. (2014) proposed that Le Clot (and thus Fordones) are younger than the PETM, older than the Eocene Thermal Maximum 2 (ETM2, 53.7 Ma), and correlated with the upper nannoplankton NP10-lower NP11 zones, near 53.8 Ma. This dating implies that Le Clot, Fordones, and possibly Palette are significantly younger than the MP7 reference-level. The unique chemostratigraphical data available for Palette (Cojan et al., 2000) consistently supports this hypothesis in positioning the fossiliferous level between two negative $\delta^{13} \mathrm{C}$ excursions, which possibly correspond to the PETM and ETM2. Finally, the Saint-Pierre-des-Champs locality, Corbières, Southern France, was recently discovered by one of us (RT) from the same thin continental level of Fordones and Le Clot, implying that this new locality is also correlated to the upper nannoplankton NP10-lower NP11 zones, near 53.8 Ma.

From Palette, we describe 25 specimens; the holotype (UCBL-FSL2084) already described by Depéret (1910) and figured by Hooker and Dashzeveg (2004) is housed at the Faculté des Sciences de Lyon (FSL), a cranium and a mandible figured by Repelin (1930) housed in the collection of the Aix-Marseille University (AMU), 19 new specimens recently discovered and housed at the Aix-en-Provence Natural History Museum, and 3 unpublished historical specimens 
from the Vasseur Collection of the AMU. The material (Table 1) includes cranio-mandibular elements, isolated teeth and some post-cranial remains.

We scanned one complete cranium (MHN.AIX.PV.2017.6.1.1 and

MHN.AIX.PV.2017.6.1.2) by microtomography in order to visualize its anatomy as precisely as possible. We also CT-scanned the cranium MHN.AIX.PV.2017.6.4, which is embedded in a thick block of limestone and is heavily fragmented. In addition, we CT-scanned and reconstructed the mandible of the juvenile specimen (MHN.AIX.PV.2018.26.3), which has suffered from deformation in its distal parts.

Comparative material studied in this work is housed in the Muséum national d'Histoire naturelle, Paris, France (MNHN.F, fossil mammal collection); the Université de Montpellier, France; the Faculté des Sciences de Lyon, France, the Geiseltalmuseum, Halle, Germany; the Institut Català de Paleontologia Miquel Crusafont, Sabadell, Spain; the Naturhistorisches Museum of Basel, Switzerland; the Geological Institute of the Mongolian Academy of Sciences, Ulaanbaatar, Mongolia; the Yale Peabody Museum, New Haven, USA and the University of California Museum of Paleontology, Berkeley, USA.

Institutional Abbreviations-AMNH, American Museum of Natural History; FSL, Faculté des Sciences de Lyon; GMH, Geiseltalmuseum; ICP, Institut Català de Paleontologia Miquel Crusafont; MHN.AIX, Muséum d'Histoire Naturelle d'Aix en Provence; MHNT, Muséum d'Histoire naturelle de Toulouse; MNHN, Muséum national d'Histoire naturelle; NMB, Naturhistorisches Museum Basel; UCMP, University of California Museum of Paleontology; UM, Université de Montpellier,

\section{METHODS}

Dental and cranio-mandibular terminology and measurements follow Vautrin et al. (2019). Dental terminology is resumed in figure 2. 


\section{CT-SCAN and Reconstruction}

The crania and the mandible of the newborn specimen were virtually reconstructed in 3D using the image data obtained via high-resolution microtomography $(\mu \mathrm{CT})$ at the MRI platform of the Institut des Sciences de l'Evolution de Montpellier (ISEM). Image segmentation was performed on the $\mu \mathrm{CT}$ images with AVIZO 9.1 (Visualization Sciences Group) software. The different segmented elements of MHN.AIX.PV.2017.6.4 and MHN.AIX.PV.2018.26.3 were replaced in anatomical position under the MorphoDig software (Lebrun, 2019).

\section{Phylogenetic Analysis}

We constructed a new morphological matrix based on the matrices of Holbrook (2009), Rose et al. (2014), Robinet et al. (2015) and Bai et al. (2018). We coded 39 taxa for 187 characters. The matrix is composed of 132 dental characters, 29 cranio-mandibular characters and 26 post-cranial characters (matrix called "extended matrix" hereafter, see below). All characters were scored based on direct observations for all lophiodontids and on direct observations and/or publications for other taxa (Tab. 2). Seventeen multistate characters that represent distinct morphoclines (characters $n^{\circ} 18$, $69,72,78,93,100,108,125,138,140,141,147,148,150,151,153,154,155,166,167,169,186)$ were ordered. Uninformative characters have been removed from the matrix, and characters identically coded in successive tooth have been fused. In order to infer the position of lophiodontids within the Perissodactyla, we included 18 lophiodontid taxa and a selection of early Chalicotheriidae and Ceratomorpha taxa previously affiliated with Lophiodon (Viret, 1958; Radinsky, 1964; Hooker and Dashzeveg, 2004; Holbrook, 2009) (Tab. 2). We coded the populations of $L$. remense from the locality of Cuis and Monthelon (Paris Basin, France) and from the Geiseltal (Germany) as distinct taxa, as the systematic of the Geiseltal lophiodontids proposed by (Fischer, 1977) has been recently questioned (Godinot et al., 2018). Pending a formal revision of the Geiseltal lophiodontids, we made a distinction between the populations from the Geiseltal and from the Paris Basin to avoid possible systematic misinterpretations. For the same reason, we coded the 
L. cuvieri material from the Paris Basin locality of Jouy and the L. cuvieri material from the Geiseltal as two taxa in our matrix. In addition, we included Homogalax and Heptodon, two genera previously used in early perissodactyl phylogenies (Hooker and Dashzeveg, 2004; Holbrook, 2009; Bai et al., 2018), as well as five hippomorph taxa (Tab. 2). The outgroup includes by one cambaythere representative, which is a composite of Cambaytherium thewissi and Cambaytherium gracilis (Smith et al., 2016) and three Paleogene ungulate-like taxa (Phenacodus intermedius, Radinskya yupingae and Hallensia matthesi), variably placed either in the polyphyletic assemblage "Condylarthra", or close to or within Perissodactyla (Franzen, 1990; Cooper et al., 2014; Rose et al., 2014 ; Smith et al., 2016).

We analyzed the matrix using heuristic search option in Paup 4.0a162 (Swofford, 2003) with 1000 replications and branch swapping with random stepwise addition with the TBR swapping algorithm. Lophiodontids display a high dental polymorphism (Vautrin et al., 2019) and thus we choose to code the polymorphism as " $0+1$ " following the recommendations of Wiens (1998). The consistency and retention indexes, as well as Bremer indexes for each node have been calculated under Paup 4.0a162. The numbers and identity of unambiguous synapomorphies have been tracked on the Mesquite software (Version 3.04; Maddison and Maddison, 2015).

Dental characters make up a very large part of the extended matrix presented above, because early perissodactyls are mostly represented by dental material. Because dental characters are sometimes convergent between perissodactyls families (Holbrook and Lapergola, 2011) and may often perform relatively poorly in phylogenetic analyses within Mammalia (Sansom et al., 2017), we added several cranial and postcranial characters from Holbrook (2009), Rose et al (2014), Bai et al., (2018) and new characters based on our own observations, to try to improve the reliability of these phylogenetic reconstructions (see Discussion). In addition, given the very large proportion of dental characters in this extended matrix, potential covariations between characters repeated at successive loci were scrutinized (see Billet and Bardin, 2018). In order to test the possible effect of 
such covariation on our reconstructed phylogenies, an alternative version of the extended matrix was built where characters repeated at successive tooth and with a high similarity in their coding were scored in a single character summarizing their variation. This was done for several characters on P3-P4, on uppers molars and on p3-p4 (SuppData 2; this matrix is called "reduced matrix"). When the state was different between successive loci in some taxa the state was coded as polymorph.

SYSTEMATIC PALEONTOLOGY

Order PERISSODACTYLA Owen, 1848

Suborder TAPIROMORPHA Haeckel, 1873

Infraorder ANCYLOPODA Cope, 1889

Family LOPHIODONTIDAE Gill, 1872

Genus LOPHIASPIS Depéret, 1910

Type Species-Lophiaspis maurettei Depéret, 1910

Included Species-Lophiaspis baicherei Depéret, 1910, Lophiaspis occitanicus (Depéret, 1910)

Emended Genus Diagnosis- Small Lophiodontidae; brachyodont and zygodont upper molars, retaining paraconules but without ectostyles; medium to large-sized canines; brachyodont and bilophodont lower molars with postectometacristid; presence of a P1; presence of C-P1, P1-P2 and c-p2 diastema; P2-P4 nonmolariform (without hypocones); postprotocrista on upper premolars connects metacone to protocone; molar metaloph (prehypocrista connecting the ectoloph) and protoloph (fusion of the preparacristule and the preprotocrista) relatively long and with hypocone, protocone, and relatively large paraconule and notched preprotocrista; p1 absent; molar prehypocristid low and directed toward the middle of the protolophid. Differs from Protomoropus 
and Paleomoropus by more posteriorly deflected protocone and hypocone on the upper molars; a more lingually tilted metacone and by a thinner lingual cingulum vanishing under the protocone and the hypocone on M1 and M2. Differs also from Protomoropus by a weaker postectometacristid on its lower molars and by a smaller hypoconulid lacking a prehypocristulid on m3. Differs from the other Lophiodontidae by a smaller hypoconulid on $\mathrm{m} 3$ and slightly enlarged trigonid on lower molars. Differs from Eolophiodon by its larger and more individualized paraconule with a deeper notch on the preprotocrista. Differs from Eolophiodon and Lophiodon by the retention of P1; larger canines, ventrally extended angular region of the mandible; thinner zygomatic arches and shorter jugal process. Differs also from Lophiodon and Paralophiodon by the presence of a distinct paraconule and a notched preprotocrista on upper molars and deciduous premolars; less quadrangular upper premolars; the absence of an endoparacrista and an ectostyle on the upper molars and deciduous premolars; the absence of an entoconid on dp2 and by the presence of a paraconid on dp3; mandibular symphysis ending at the p2 level; more concave glenoid cavities; retention of a postglenoid foramen and slender post-cranial elements.

\section{LOPHIASPIS MAURETTEI Depéret 1910}

(Fig. 3-9)

Emended Diagnosis-Differs from Ls. occitanicus and Ls. baicherei by its smaller size; a larger and more individualized paraconule; deeper notch on the preprotocrista on the upper molars. Differs also from Ls. occitanicus by smaller hypoconulid on m3; a slightly enlarged trigonid and a preentocristid on lower molars.

Holotype-FSL 2084, fragmentary palate with right P2-M3 and left P3-M2

Referred Specimens-See table 1.

Occurrences and Distribution-Palette, Early Eocene, younger than MP7 (Cojan et al., 2000, Yans et al., 2014) possible presence in Silveirinha and St-Pierre-des-Champs 


\section{Description}

Cranium-All specimens have suffered of synsedimentary compression (dorso-ventrally for MHN.AIX.PV.2017.6.1.1 and MHN.AIX.PV.2017.6.4 and medio-laterally for AMU13084). The nasal bone is long, narrow rostrally and wide nuchally, and overlays the premaxilla (Fig. 3, 3A-B). The nasal incision ends rostral to the canines (Fig. 3B, 3B). The nasal exhibits a long and large transverse suture with the frontal (Fig. 3A,C, 3A). The maxilla is broad and high. The anterior opening of the infra-orbital canal is preserved above P4 on MHN.AIX.PV.6.1. The lacrimal is crushed on both skulls and there is no naso-lacrimal connection on MHN.AIX.PV.2017.6.4 (Fig. 4B). On the other skull, the lacrimal is not visible due to the crushing of bones. The rostral edge of the orbit is located at the level of M2. The nuchally-oriented post-orbital processes are massive, short, and partly broken. The presence of supraorbital foramen cannot be attested due to the damage of the post-orbital processes. The temporal lines join just nuchally to the orbit (Fig. 3A,C). Although the dorsal profile of the skull is largely damaged, the sagittal crest is partly preserved on both specimens. It is sharp and much higher dorsally than the anterior part of the skull (Fig. 4B, D), which probably conferred a dome-shape to the fronto-parietal region. The post-orbital constriction is strong in dorsal view (Fig. 3A,C, 3A). The braincase is small and slightly swollen in dorsal view (Fig. 3A,C, 3A). The nuchal crests are wide, strongly inclined nuchally (Fig. 4B,D) and form a flat angle, in dorsal view, at the junction with the sagittal crest. The nuchal crests are highly curved and extend rostrally to the lateral portions of the paraoccipital process (Fig. 3A,C, 3D). The zygomatic arches are transversally thin and enlarged at the M2 level. The jugal bears a short post-orbital process more nuchally placed than the process of the frontal (Fig. 3A,C, 3B). The zygomatic arches are low. The dorsal edge of the nuchal part of the zygomatic arches is lower than the superior edge of the orbit. 
The palate is flat, except at the C-P1 diastema level where it shows a slight concavity. The choanae open at the level of the anterior half of M3 (Fig. 3B,D; 3B, D) and are not surrounded by a torus. Two major palatine foramina open at the level of the anterior edge of M3 for the major palatine nerve and vessels (Wible and Rougier, 2000), just rostro-lateral to the aperture of the choanae on MHN.AIX.PV.2017.6.1.1 (Fig. 3B,D). The pterygoid laminae are high and blade-like. The interpterygoid is narrow. The vomer and the presphenoid are not visible. The posterior opening of the alisphenoid canal opens directly rostro-lateral to the pterygoid lamina (Fig. 3B,D, 3C). The foramen ovale opens just posterior to the alisphenoid canal (Fig. 3B,D, 4). The pyriform fenestra opens just caudally to the foramen ovale. The two foramina are not confluent and are separated by a ridge, the tympanic process of the alisphenoid (Fig. 3B, 4).

The glenoid cavity has an oval shape and is slightly concave (Fig. 3B,D, 3C). The postglenoid processes are wide, long transversally and the anterior facets are slightly oriented rostro-laterally in MHN.AIX.PV.2017.6.1.1 (Fig. 3B,D). A small postglenoid foramen is present just posteromedial to the postglenoid-process (Fig. 3B,D, 4). The post-glenoid and the post-tympanic process of the squamosal are separated and the external auditory meatus is open ventrally (Fig. 3B). The post-tympanic process is slightly shorter than the postglenoid process (Fig. 4D). This character is present in eomoropids and is interpreted as evidence of the presence of an auditory bulla (Holbrook, 2001). However, the basicranium is crushed in all specimens from Palette and no fragment of auditory bulla is visible (Fig. 3B, 3C, 4). The absence of fragments could indicate either an absence of bulla or a loose attachment of the ectotympanic bones with the skull as in tapiromorphs (Radinsky, 1965; Holbrook, 2001). The post-tympanic process forms the posterior margin of the external auditory meatus. The paroccipital processes are broken in all specimens. The right petrosal is preserved in MHN.AIX.PV.2017.6.1.1. The fenestra vestibuli (oval window) of the petrosal opens laterally and the external aperture of the cochlear fossula (leading internally to the fenestra cochleae) opens ventrally and distally (Fig. 5). There is no nutrient foramen on the lateral 
side of the petrosal. Posterior to the secondary facial foramen, the facial sulcus is very thin but deep (Fig. 5). Posteriorly, the fossa for the stapedius muscle is well-marked and elongated. The occipital condyles are low and are transversally elongated. The hypoglossal foramen opens behind the base of the paroccipital process, laterally to the occipital condyles (Fig. 4C).

Due to the lack of material of comparison, the complete description of the internal and external anatomy of the petrosal as well as other internal preserved cranial structures of $L s$. maurettei will be included in another study, with the inclusion of new material from other early diverging perissodactyls and lophiodontids.

Mandible-The rostral part of the mandible (MHN.AIX.PV.2017.6.1.2) is long and thin with a great transversal constriction at the c-p2 diastema. The symphysis is strong, totally fused, and ends at the level of $\mathrm{p} 2$. The mandibular body increases in height under the diastema but is constant under the cheek teeth (Fig. 6A,C, Tab. 3). Three mental foramina are visible on the adult specimen (Fig. 6A,C). The most anterior foramen is located below the canine-p2 diastema. The second foramen is present below the $\mathrm{p} 2$. The most posterior foramen is located below the $\mathrm{p} 3$. The incisura vascularis is relatively long but not deep. The mandibular angle is broad and is greatly extended ventrally and slightly nuchally (Fig. 6A,C). The coronoid crest forms a nearly right angle and does not overhang the molars. The tip of the coronoid process forms a small hook distally (Fig. 6A,C). The incisura mandibulae (mandibular notch) is short but deep (Fig. 6A,C). The condylar process is bulbous and long rostro-nuchally (Fig. 6B,D). The posterior edge of the ascending process is relatively flat with a small concavity under the condylar process (Fig. 6A,C).

The juvenile mandible (MHN.AIX .PV.2018.26.3) displays a non-erupted $\mathrm{m} 1$ and lacks germs for the last molars or the premolars. It exhibits unworn deciduous premolars (dp2-4).

This juvenile mandible is more gracile than the above-described adult mandible. The canines are missing but the diastema between the canine alveoli and the dp2 is long (Fig. 6E-F, Tab. 3). The symphysis ends rostrally to the $\mathrm{dp} 2$. The mandible is proportionally less high under the tooth row 
(Fig. 6E-F, Tab. 3) than in the adult. Four mental foramina are present, under the c-p2 diastema, the dp2, the dp3 and under the dp4 (Fig. 6E-F). The mandibular angle is less ventrally enlarged than in the adult but is slightly more extended nuchally. The incisura vascularis is not marked, and nearly not visible. The ascending branch is more posteriorly inclined than in the adult specimen. The incisura mandibulae is shorter and deeper in the juvenile than in the adults (Fig. 6E-F).

Upper Teeth-The upper incisors are represented by the I3 in AMU13084. The I3 has a semicircular crown and is constricted transversally, with a slightly concave lingual side (Fig. 7H). The I3 and the canine are separated by a diastema on AMU13084 (Fig. 7H). The canines lack cingula at their cervix (Fig. 7D-E). The canine of AMU13084 has a medium size (Fig. 7D, Tab. 4), it is slightly curved and lacks crests. The root is mesiodistally extended but is constricted transversally. The canine of MHN.AIX.PV.2018.26.1 is broader with a wider root (Tab. 4, Fig. 7E). The canines of MHN.AIX.PV.2017.6.1.1 and MHN.AIX.PV.2017.6.4 are absent but their alveoli are broad and similar in size with MHN.AIX.PV.2018.26.1.

The $\mathrm{P} 1$ is separated from the canine by a long diastema (Fig. 3B,D). The P1 is unicuspid and is constricted labiolingually (Fig. 3B,D). It has two roots sagittally aligned. The cingulum, nearly absent, is only distally present. The P1 and P2 are separated by a diastema (Fig. 3B,D).

The $\mathrm{P} 2$ is triangular in occlusal view with a distally placed protocone. The parastyle is absent (MHN.AIX.PV.2019.5.1) or small. On AMU13084, MHN.AIX.PV.2019.5.1 and AMU70397 (SuppData 3, Fig. S1), the P2 has a unique labial cusp. The paracone is high and broad, the short preparacrista joins the parastyle. A small metacone is present on AMU200196 and on MHN.AIX.PV.2017.6.1.1 (Fig. 7A-B). The two labial cusps are nearly fused and are only separated by a shallow labial groove. There is no endoparacrista. The protocone is broad but low and is strongly distally placed (Fig. 7A-B). A small preprotocrista is present on MHN.AIX.PV.2019.5.1. This tooth presents a broad basin distolabially to the protocone (Fig. 7A-B). The cingulum is very thin lingually and slightly thicker labially under the parastyle and the metacone. 
The $\mathrm{P} 3$ is triangular in occlusal view. The parastyle is higher and more distinct than in P2. The paracone is high and broad. There is no endoparacrista. The metacone is twinned with the paracone. The two cusps are separated by only by a shallow labial groove and a slight lingual depression. The metacone is slightly more lingual than the paracone on the holotype UBCL-FSL 2084, MHN.AIX.PV.2017.6.1.1, and MHN.AIX.PV.2019.5.1 (Fig. 7A-C) but is sagittally aligned on AMU70397 and AMU13084. Labially, the metacone is relatively flat in the holotype and is more convex on the other specimens. A small endometacrista is present lingual to the metacone. The postmetacrista reaches the distal edge of the tooth. The preprotocrista is short, oriented mesiolabially and does not join the ectoloph. All the specimens, except MHN.AIX.PV.2019.5.1 and the right P3 of FSL2084, display a blunt postprotocrista oriented toward the endometacrista. In AMU13084 a small endoprotocrista is oriented distally. The crista is short and does not join the edge of the tooth. The cingulum is thin mesio-distally and is very thick lingual to the metacone and the parastyle.

The P4 is wider labiolingually than the P3 (Tab. 4). The parastyle is higher and more labial. The paracone and the metacone are more distinct from each other than on the P3. The paracone is strongly convex labially and does not present an endoparacrista lingually. The metacone is smaller than the paracone and is more lingual. The metacone is labially flat on all specimens, except in MHN.AIX.PV.2019.5.1. The protocone is broader and higher than on P3. The preprotocrista is longer and joins the ectoloph at the junction of the postparacristule and the preprotocrista. The postprotocrista is present and joins the endometacrista. The postprotocrista is blunt in MHN.AIX.PV.2019.5.1 and salient in other specimens. Unlike P3, there is no endoprotocrista. The cingulum is thin mesially and distally. On AMU13084, a thin cingulum is visible lingual to the protocone. The cingulum is thick labial to the metacone and the parastyle.

The upper molars are quadrangular. All molars present a prominent parastyle. The parastyle on M1 is slightly more labial than the paracone and the two cusps are separated by a deep groove. 
The parastyle of M1 bears mesially a preparacristyle oriented lingually which contacts the distal end of the P4 postmetacrista. Distally, a short postparacristyle joins the preparacrista. The paracone is high and broad with a convex labial side. The lingual side of the paracone is convex but does not present an endoparacrista. The metacone is slightly smaller than the paracone and is more lingually placed. The metacone is labially flat with a small middle convexity. The metacone and the paracone are linked by a straight centrocrista. The molars do not present an ectostyle. The protocone and hypocone are equal in size with the protocone being slightly more lingual. The molars present a broad and distinct paraconule (Fig. 7A-C). A small notch is visible lingually to the paraconule on the preprotocrista. The hypocone is extended labially by a prehypocrista that joins the ectoloph just mesial to the metacone. There is no distinct metaconule. The metaloph and the protoloph are slightly oblique and parallel to each other. The cingulum is thin mesially and distally and is thick labial to the paracone and the metacone. The lingual cingulum is thin and interrupted lingual to the protocone and the hypocone on all molars, except on the M3 of MHN.AIX.PV.2017.6.1.1. The M2 is larger and slightly broader than M1 but has an overall similar morphology. The parastyle is more labial and the groove separating the parastyle and the paracone is broader than on M1. On AMU13084, an endoparacrista is still visible despite the damages on the specimen. On other specimens, the paracone is lingually convex but does not present any endoparacrista. The metacone on M2 is flatter than on M1 and does not show any convexity. The parastyle of M3 is broader and projected more labially than on other molars giving a trapezoidal outline to the tooth (Fig. 7A-C). The metacone is less lingually oriented and is slightly more labial than on M2.

Lower Teeth-The lower incisors have a spatulate crown. The labial border of the incisors is slightly convex and the lingual part is concave, giving a shovel form to the teeth. The i1 and i2 have quite similar size. The i3 is broken on AMU20020 (See SuppData 3, Fig. S2). The anterior part of the mandible have been reconstructed with resin (SuppData 3, Fig. S2;S3). Thus, the exact position of the incisors cannot be asserted. However, the i3 is pushed against the canine, suggesting an 
absence of incisor-canine diastema as in other lophiodontids. The canines of MHN.AIX.PV.2017.6.1.2 are strong, high and slightly curved (Fig. 6A). The lower canines are constricted transversally and are slightly curved. There is no mesial or distal crest and the cingulum does not form a "bud" at the cervix. The lower canines present long wear surfaces due to the contact with the upper canine and the I3. The canine of AMU20020 is smaller and straighter. The canine is separated from the cheek teeth by a long diastema (Fig. 6A).

There is no $\mathrm{p} 1$. The $\mathrm{p} 2$ is oval in occlusal view (Fig. 7I). A small metaconid is present on the AMU20020 (Fig. 7K) but is absent on MHN.AIX.PV.2017.6.1.2. A small paraconid is linked to the protoconid by a small preprotocristid on AMU20020, but is absent in MHN.AIX.PV.2017.6.1.2 (Fig. 7I,K). The hypoconid is central and the prehypocristid reaches the basis of the protoconid on MHN.AIX.PV.2017.6.1.2. and between the protoconid and metaconid on AMU20020. The hypoconid bears a short lingual posthypocristid. The entoconid is absent. The $\mathrm{p} 3$ is wider labiolingually (Tab. 4) and is more quadrangular than p2. A small paraconid is present mesially (Fig. 7I). The protoconid is twinned with the metaconid. The two cusps are equal in width and length and the metaconid is more distally placed. The trigonid and the talonid have the same width (Tab. 4). The hypoconid is central and the prehypocristid joins the protolophid between the protoconid and the metaconid. The entoconid is absent. The $\mathrm{p} 4$ is quadrangular with a wider trigonid than $\mathrm{p} 3$ (Tab. 4). The paraconid is absent. The metaconid is more distant from the protoconid than on $\mathrm{p} 3$. As on $\mathrm{p} 3$, the metaconid is distal to the protoconid. On the $\mathrm{p} 4$ of the mandible figured by Repelin a strong postectometacristid is present (Fig. 7K). The hypoconid is more labial than on $\mathrm{p} 3$. The posthypocristid is salient and lingually oriented. A small entoconid is present on AMU20020, but is absent on MHN.AIX.PV.2017.6.1.2 (Fig. 7I,K).

The lower molars are quadrangular and bilophodont. The protolophid is formed by the postprotocristid and the postmetacristid, and the hypolophid is formed by the posthypocristid and the postentocristid. The $\mathrm{m} 1$ is very worn on all specimens and most of the cristids are not visible. 
The protolophid and the hypolophid are slightly oblique and parallel to each other. The prehypocristid joins the protolophid at its basis and midlength (Fig. 7I). The cingulum is thick mesialy and distally, and thin on the labial side of the teeth. Lingually, the cingulum is not visible. On the $\mathrm{m} 2$, the preprotocristid reaches the mesial side of the teeth. The entoconid is slightly more distal than the hypoconid. The entoconid displays a short preentocristid (Fig. 7I). On m3, a short postectometacristid is visible distal to the metaconid (Fig. 7I). The entoconid is damaged and the presence of a preentocristid cannot be observed. The talonid is narrower than the trigonid (Tab. 4). The lingual and the labial walls of this tooth are not parallel but slightly convergent distally. The hypoconulid is low and has the same size as the hypoconid. The hypoconulid does not present a prehypocristulid.

Lacteal Dentition-The DP4 is fully molarized and is morphologically similar to the M1. The protocone and the hypocone are equally developed (Fig. 8A), the protoloph and the metaloph are more oblique than on upper molars (Fig. 8A), the paraconule is broad and the preprotocrista is notched. The lingual side of the paracone is convex and there is no endoparacrista (Fig. 8A). There is no ectostyle between the paracone and the metacone and the metaconule is absent.

The dp2 is simple (Fig. 8E-F) with a broad mesial distinct paraconid, a high protoconid and a low hypoconid. The postprotocristid is blunt and oriented toward the disto-lingual corner of the tooth (Fig. 8E-F). A short prehypocristid connects the hypoconid to the protoconid. The metaconid and the entoconid are absent.

The dp3 has a triangular outline in occlusal view (Fig. 8E-F). The paraconid is broad, while the metaconid is small and twinned with the protoconid. The hypoconid is broader and higher than in dp2. The posthypocristid is salient and joins a high and well-defined entoconid. The entoconid presents a short preentocristid (Fig. 8E-F).

The dp4 is broader than the dp3 and more molariform. Its morphology is nearly identical to the $\mathrm{m} 1$ (Fig. 8E-F). The paraconid is absent and the preprotocristid is curved and connected to the 
mesial basis of the metaconid. The metaconid is high, well defined and distinct from the protoconid. A strong postectometacristid forms a metastylid (Fig. 8E-F). A short preentocristid is present mesial to the entoconid.

Postcranials-The postcranial elements have not been found in association with the dental material of Ls. maurettei. The specimens have been attributed to Lophiaspis maurettei after comparison with Lophiodon and Paralophiodon (Depéret, 1907; Holbrook, 2009) and other postcranial elements of early perissodactyls (Osborn, 1913; Colbert, 1934; Radinsky, 1965; Wood et al., 2011; Bai et al., 2017).

The scapula is dorso-ventrally crushed and the dorsal part is broken (Fig. 9A). The glenoid cavity is oval in shape and is slightly constricted dorsoventrally. The cavity is slightly concave but is not deep. A coracoid process is present on the dorsal edge of the glenoid cavity. The process is rectangular and robust and is slightly curved medially, forming a hook. The coracoscapular notch is shallow. The infraspinous fossa is smaller than the supraspinous fossa. The scapular spine is straight, high and salient. The tip of the spine is deformed and fold toward the supraspinous fossa. The acromion is broken but its basis is still visible.

The innominate is heavily damaged (Fig. 9B). The acetabulum has an oval shape in lateral view and is $23.7 \mathrm{~mm}$ wide and $13 \mathrm{~mm}$ deep. The edges of the acetabulum are high and broad, with a flat dorsal margin. The ilio-pectineal line tuberosity is prominent, rough and narrow and is bordered cranially by a shallow notch. Ventrally to the tuberosity, the specimen presents an oval shaped depression corresponding to the attachment of the rectus femoris.

The tibia is strongly compressed transversally and the proximal epiphysis is absent (Fig. 9C). The tibia is long and slender. The tibial crest is deformed and folded against the diaphysis. The distal extremity of the crest forms an oval rugosity for the insertion of the cranial tibialis muscle. Distally, the lateral process is long and broad and is slightly curved medially. 
The articular surface with the astragalus is asymmetric. The medial surface is broad, oval in shape and is concave. The lateral facet is narrower, deeper and is extend craniocaudally. The two facets are separated by a blunt ridge. The medial maelleolus is high and broad.

The astragalus is relatively high and slender with a non-oblique throchlea (Fig. 10A; Tab. 5). The medial ridge of the trochlea is narrow and steep. The lateral ridge is wider and extends more proximally. The medial side of the neck of the astragalus is concave. The lateral portion bears a strong tubercle (Fig. 10A-B). The sustentacular facet is flat, rectangular and distally extended (Fig. 10B). The sustentacular and navicular facets are separated by a narrow sulcus. Another sulcus, deeper and broader, separates the sustentacular and ectal facets (Fig. 10B). On MHN.AIX.PV.2019.5.9, the distal calcaneal facet is triangular and does not join the sustentacular facet (Fig. 10B). On MHN.AIX.PV.2019.5.1, the facet is more striplike and laterally extended, and joins the sustentacular facet. Ventrally, the distal calcaneal facet contacts the cuboid facet at a nearly right angle. The ectal facet is located on the caudal part of the lateral tubercle of the astragalus. The facet is fan shaped, slightly concave and caudo-dorsally oriented (Fig. 10B). Distally the navicular facet is saddle-shaped as in other perissodactyls (Holbrook, 2001). The navicular facet contacts laterally the cuboid facet forming an obtuse angle. The cuboid facet is strip-like, thinner medially and slightly concave.

The calcaneum is long with a transversally compressed tuber (Fig. 10C-D; Tab. 5). The proximal part of the tuber is rugose and oval. The ectal facet faces distally, at a nearly right angle with the long axis of the calcaneum. The ectal facet is crescentiform and slightly concave. A shallow depression for the distal part of the fibula is located posterodorsally to the ectal facet. A broader and shallower depression is located proximally to the junction of the ectal and sustentaculum facets of the calcaneum. The facet is oval and slightly oblique (Fig. 10C-D). The distal astragalar facet is striplike and convex (Fig. 10C). The cuboid facet is crescentiform with a broader cranial part. A small posteromedial pit is present on the cuboid facet. There is no surface of 
contact with the navicular confluent with the distal astragalar facet. The distal end of the calcaneum does not present a peroneal tubercle.

The third metatarsal is long $(73 \mathrm{~mm})$ and thin $(11.5 \mathrm{~mm})$ (Fig. 9D-F). The specimen has been compressed ventrally during the fossilization. The articular surface for the ectocuneiform is reiniform and slightly convex. Proximoposteriorly, the metatarsal presents a small rectangular and convex surface for the articulation of the MT I (Fig. 9E). Medially to the proximal head the bone surface is rugose and presents two small surfaces for the MT II (Fig. 9E). The proximomedial surface is circular, small and slightly convex. The proximal caudal surface is broader, more quadrangular and flatter. Two articular surfaces are present on the lateral side for the MT IV, separated by a narrow sulcus (Fig. 9F). The distal articular surface is convex and bears a sharp keel. The pit for the insertion of the flexor ligaments are deep (Fig. 9E-F).

The proximal phalanx is high $(19.9 \mathrm{~mm})$ and thin $(8.9 \mathrm{~mm})$. The proximal surface has an oval outline and is concave. Proximo-caudally, the surface margin presents an indentation (Fig. 9G) flanked by two tubercles. The median groove is narrow and shallow. The body of the phalanx is convex anteriorly and slightly concave posterioly. The distal articular surface is laterally flanked by two small pits for the insertion of the flexors ligaments.

The medial phalanx is shorter $(11.8 \mathrm{~mm})$ and relatively wider $(8 \mathrm{~mm}$; Fig. 9I-J). A faint ridge splits the articular surface in two semi-circular surfaces. The two surfaces are equal in size and slightly concave. The medial phalanx does not present an indentation of the posterior margin of the proximal surface. The surfaces for the insertion of the flexor ligaments are relatively broader and deeper than on the proximal phalanx.

\section{COMPARISON}


Some early Eocene specimens from Europe have been described as close to Ls. maurettei, on the basis of the upper molar morphology (Savage et al., 1966; Estravis, 1992; Checa Soler, 1997). We compare these specimens with the new material from the type locality and propose a systematic revision of the species.

\section{Comparison with Putative Ls. maurettei from Other Localities Close to MP7}

Silveirinha: A small tooth found in the older MP7 Portuguese locality of Silveirinha (Marandat et al., 2012) was identified as an upper molar and assigned to cf. Lophiaspis maurettei (Estravis, 1992). Only the metacone, part of the paracone and lophs are preserved (Fig. 8D). The specimen is smaller than the molars of Palette and presents slightly more oblique lophs; in this aspect, it resembles more the DP4 MHN.AIX.PV.2019.5.3 of Ls. maurettei from Palette and deciduous premolars of other lophiodontids (Fig. 8). In addition, as in MHN.AIX.PV.2019.5.3, the metacone is flat and slightly tilted lingually. There is a trace of a paraconule as well as a small notch in the preprotocrista which is diagnostic in Ls. maurettei. However, the cingulum labial to the metacone is broader and forms an ectostyle (Fig. 8D), which is absent in the deciduous teeth from Palette. Such polymorphism is known for upper molars of Lophiodontidae (Vautrin et al., 2019) and might also be present on deciduous teeth. We propose to assign the specimen to Ls. maurettei as a DP4. Thus, if the relative dating of the localities proposed by Marandat et al. (2012) is correct, the specimen from Silveirinha is the oldest known specimen of Lophiaspis maurettei.

Saint-Pierre-des-Champs: The specimen (UM-SCP-1, Fig.7L) from the new locality is badly preserved but the tooth is quadriscuspidate and bilophodont. Most of the characters have been erased. However, the size and morphology of the tooth are similar to the $\mathrm{m} 1$ of Ls. maurettei. The mesial cingulum is still visible and the trigonid basin is short. The mesial part of the prehypocristid contacts the protolophid at midpoint as in Ls. maurettei. However, the lingual part of the tooth is greatly damaged and the presence/absence of lingual cristids cannot be assessed. Due to its size, its 
bilophodont morphology, the short trigonid basin and the orientation of the prehypocristid, we proposed to assign tentatively this tooth as a $\mathrm{ml}$ of Lophiaspis ? maurettei.

\section{Comparison with Putative Ls. maurettei from MP8+9 and MP10 Localities}

Mutigny MP8+9: Upper and lower isolated teeth from the locality of Mutigny in the Paris Basin were attributed to Ls. maurettei by Savage et al. (1966). The teeth of Mutigny (MNHN.F.MU12299, MNHN.F.MU-194-L, MNHN.F.MU-195-L, UCMP 63667, UCMP 66353 and UCMP 68037) are slightly larger than the holotype (15\%) but present the diagnostic characters of $L s$. maurettei. The M2 (UCMP 63667) bears a broad paraconule, with a notched preprotocrista, and the ectostyle is absent (Savage et al., 1966). The premolars are plesiomorphic with a salient postprotocrista connecting the metaloph and forming a V as in Ls. maurettei from Palette. Although a small paraconule is present on one P4 (MNHN.F.MU-195-L), this conule is absent in the specimens from Palette. However, such polymorphism is present in early Lophiodontidae (Vautrin et al., 2019).

The trigonid basin of MNHN.F.MU-194-L is wider and longer than in MHN.AIX.PV.2017.6.1.2 (Fig. 7J) and the labial and lingual walls are parallel and not convergent. The postectometacristid is larger than in the Palette specimen and forms a metastylid (Fig. 7J) as in Litolophus or Protomoropus (Hooker and Dashzeveg, 2004; Bai et al., 2010). However, instraspecific size variation of the postectometacristid is known in other lophiodontids (Vautrin et al., 2019). In E. laboriense and L. lautricense the postectometacristid varies from medium size to very weak, and the cristid is even absent in some specimens.

Due to the size and morphological differences observed, we propose to change the determination of the material from Mutigny to cf. Lophiaspis maurettei.

Les Salères, MP10: Two upper molars from Northern Spain have been assigned to Lophiaspis maurettei because of the presence of a paraconule (Checa Soler, 1997). The specimens 
are indeed very similar to Ls. maurettei of Palette, with the absence of an ectostyle and of an endoparacrista. However, the presence of the paraconule remains ambiguous in the Spanish specimens. The protoloph of both specimens is worn, with badly preserved enamel and the protoloph is not thicker at the emplacement of the paraconule as observed in the specimens of Palette (Fig. 7F-G). Moreover, there is no trace of a notch on the preprotocrista (Fig. 7F-G) as in the Lophiodontinae (Robinet et al., 2015). The morphology of the molars protoloph, without paraconule, is similar to that of Lophiodon, and the absence of ectostyle and endoparacrista is also observed in some specimens of Lophiodontinae (Godinot et al., 2018; Vautrin et al., 2019). Two small species of Lophiodon are present in geographically and temporally close localities (Corsà III, Sant Miquel, Corral de l'Andreu Sud IV) (Checa Soler, 1997). Pending new specimens, we attribute the two upper molars from Les Salères to Lophiodon sp.

\section{Comparison with Other Lophiaspis Species}

The fragmentary holotype of Lophiaspis baicherei Depéret, 1910 (UML-FSL3099) from the temporally poorly constrained upper Ypresian locality of Bagnoles (Aude, France) displays a similar morphology to Ls. maurettei but it differs by some features (Depéret, 1910). Lophiaspis baicherei is larger, it presents a blunt endoparacrista and a longer metacone on its upper molars, with a shallower notch on the preprotocrista. Lingually, the cingulum of the molars is thicker and is uninterrupted below the protocone. Checa Soler (1997) attributed to Ls. baicherei several toothless mandibles and a maxillary (IPS-3747) from the MP10 of El Mas de Montayana, Spain. These specimens differ from Ls. maurettei by their larger size, the presence of a salient endoparacrista on M1-M2, a slightly reduced paraconule and a shallower notch of the preprotocrista.

Lophiaspis occitanicus (Depéret, 1910) from the ?post-Ypresian localities of Issel and La Livinière, is larger than Ls. maurettei and differs from it by a broader and higher hypoconulid on $\mathrm{m} 3$ (see differential diagnosis of Ls. maurettei above), a lack of preentocristid and postectometacristid, 
parallel labial and lingual walls of the $\mathrm{m} 2$ and $\mathrm{m} 3$ and a more distant protoconid from metaconid on the p3 (see Cuvier, 1822).

The specimens of Ls. occitanicus from the Montpellier area (close to MP10) (Roman and Gennevaux, 1907; Depéret, 1910) differ from Ls. maurettei in having a smaller paraconule and a shallower notch of the preprotocrista on the M3. The metacone is longer mesiodistally on M2-M3 and is slightly more convex. On the lower molars, the postectometacristid and the preentocristid are absent. Finally the labial and lingual walls of the m2-m3 are parallel and not convergent.

\section{Comparison with Other Genera of Ancylopoda and Lophiodontids}

Paleomoropus jepseni (Wasatchian0-2) from Wyoming is morphologically very similar to Ls. maurettei (Radinsky, 1964). The North American species mostly differs from Ls. maurettei by its metacone that is less lingually tilted on upper molars. In addition, the protocone and hypocone are less deflected posteriorly and the lophs are lower (see diagnosis of the genus Lophiaspis above). The paracone is less convex and less labially extended on the M3. The cingulum is lingually thicker and does not show interruption lingual to the protocone and the hypocone on all molars.

Protomoropus gabuniai (Hooker and Dashzeveg, 2004) from the quarry of Tsagan Kushu (Bumbanian) in Mongolia, is morphologically very close to Ls. maurettei but it differs from it by the following characters: Protomoropus gabuniai is smaller than Ls. maurettei, the paracone of upper molars of P. gabuniai (PIN.3104-323, PSS.20-220) is less lingual than in Ls. maurettei and is labially pinched, the metacone is less lingually tilted, the lingual cingulum is continuous on molars, the metacone is convex labially on the DP4 (PSS.20-55, PSS.20-56) and not flat. Moreover, the hypoconulid of the m3 of Protomoropus (PSS.20-9, PIN.3104-481) is wider, surrounded by thicker cingulum and displays a salient prehypocristulid. The postectometacristid of the lower molars (PSS.20-9, PIN.3104-480, PIN.3104-481) is stronger and forms a twinned metaconid. The cingulum is also stronger labially on the lower teeth. 
Eolophiodon laboriense from La Borie (MP8+9, France) is better known than the previous lophiodontids (Robinet et al., 2015) and its well-preserved material allows a more extensive comparison with Ls. maurettei. Eolophiodon laboriense differs mainly from Ls. maurettei by its larger size, the absence of diagnostic P1 and smaller and less distinct paraconule on the upper molars. On the M3, the metacone is less labial than in Ls. maurettei in few specimens (e.g. MHNT.PAL.2018.3.3). The canines of E. laboriense are relatively smaller than those of Ls. maurettei. The $\mathrm{P} 2$ of $E$. laboriense presents a less distal protocone and smaller occlusal basin than in Ls. maurettei. The P3 of E. laboriense lacks the lingual furrow between the paracone and the metacone. On lower molars, the postectometacristid is weaker in E. laboriense and is even absent in few specimens (e.g. MHNT.PAL.2018.3.7, UM BRI 6; Vautrin et al., 2019). The hypoconulid is broader and higher on $\mathrm{m} 3$ with parallel labial and lingual wall (see diagnosis of Ls. maurettei above). The deciduous teeth of E. laboriense differ by the presence of an ectostyle on the DP3-4 (Fig. 8B-C), broader paraconid and more distant protoconid from metaconid on the dp3, and by the absence of a preentocristid on the dp3-4 (Fig. 8G). The mandibles of E. laboriense display relatively smaller mandibular angle, less ventrally extended, with smaller concavity under the condylar process. The incisura vascularis is shorter and less marked. The condylar process is less bulbous and more blade-like. The zygomatic arches are thicker and higher. Ventrally, the choanae and the palatine foramens are more rostral in E. laboriense and the choanae are surrounded rostrally by a torus. The glenoid cavity is more extended rostrally. The postglenoid processes are more rostro-laterally oriented and are subequal in size with the post-tympanic processes.

Lophiodon and Paralophiodon are the most recent and the best known lophiodontids. Both genera differ from Ls. maurettei by a series of characters already mentioned by several authors (Filhol, 1888; Depéret, 1907; Butler, 1952; Savage et al., 1966; Dedieu, 1977; Holbrook, 2009; Vautrin et al., 2019). The cranium of Lophiodon-Paralophiodon differs from Lophiaspis by the same features as for E. laboriense, with the addition of a less concave glenoid cavity and the 
absence of the postglenoid foramen. On the mandible the symphysis ends more distally, at the level of p3 or p4 in Lophiodon-Paralophiodon. The mandibular angle is less ventrally and distally extended. Among dental characters, Lophiodon-Paralophiodon differs from Lophiaspis by their absence of $\mathrm{P} 1$, their premolars more quadrangular in occlusal view, and by their absence of paraconule and notched preprotocrista on upper molars. The canines of Lophiodon-Paralophiodon display a bud of cingulum at the cervix. The parastyle of M1 and the metacone of M3 are less labial. The M3 has a more triangular outline in Paralophiodon and varies in shape from triangular to quadrangular in some species of Lophiodon. Furthermore, the upper molars display an ectostyle and an endoparacrista, which are polymorphic in L. aff. eygalayense and L. lautricense. The postectometacristid is weaker or absent on lower molars and the hypoconulid is broader and higher on the m3. The deciduous upper teeth of Lophiodon lack the paraconule on the protoloph and they present an endoparacrista and a strong ectostyle (Fig. 8H). The DP3 is more quadrangular (Fig. 8H) than in Ls. maurettei. The lower deciduous teeth are more molariform in Lophiodon (Fig. 8I). The paraconid is broader on $\mathrm{dp} 2$ and the entoconid is well defined. The protoconid and the metaconid are more distant and the dp3 lacks the paraconid. The postectometacristid of the deciduous teeth is fainter in the specimens attributed to Lophiodon-Paralophiodon (Fig. 8I). A small metaconid is also present on the dp2 of P. leptorhynchum from Cesseras (UM CES 4224) and the preentocristid is always absent on all its lower deciduous teeth.

Regarding the postcranial elements, Lophiodon appears more massive than Ls. maurettei. The astragalus is broader and shorter, and the angle between the cuboid and the calcaneal facet is flatter in L. tapirotherium, L. rhinocerodes and L. lautricense. The calcaneum presents a broader ectal facet. The phalanges are shorter and broader in Lophiodon than in Ls. maurettei. 
The analysis of the extended matrix (see Material and Methods) resulted in 440 most parsimonious trees. The strict consensus is 581 steps long (Fig. 11). The homoplasy index is 0.65 , the re-scaled consistency index is 0.21 and the retention index is 0,60 . These later indexes are similar to those found in other phylogenies of basal Perissodactyla (Holbrook and Lapergola, 2011; Robinet et al., 2015) and is the result of important dental convergences between various perissodactyl families (Radinsky, 1969; Holbrook, 2009; Holbrook and Lapergola, 2011).

Lophiaspis maurettei is positioned as the sister taxa of all the other Lophiodontidae (Fig. 11). The monophyly of the Lophiodontidae is supported by two of unambiguous synapomorphies : the presence of an endoparacrista on the M1-M2 $\left(55^{1}\right)$ and an interruption of the lingual cingulum in front of the protocone and the hypocone on the M1-M2 $\left(187^{1}\right)$.

The other species of Lophiaspis are branched on a polytomy with E. laboriense and the clade gathering Lophiodon and Paralophiodon. This node is supported by the loss of the P1 $\left(7^{1}\right)$ which is non-homoplasic, and by two other unambiguous synapomorphies but with a low consistency index : the presence of an endoparacrista on the M3 $\left(73^{1}\right)$ and the absence of a postectometacristid on the lower molars $\left(104^{0}\right)$.

The Lophiodon-Paralophiodon clade is supported by 12 unambiguous synapomorphies: a triangular non labiolingually compressed P2 $\left(18^{1}\right)$, a parastyle lingually less extended than the paracone $\left(50^{0}\right)$, absence of a distinct paraconule on the molars $\left(61^{1}\right)$, unotched preprotocrista $\left(63^{1}\right)$, a metacone on M3 at the same position as on $\mathrm{M} 2\left(72^{1}\right)$, a broad cingulum at cervix of the lower canine $\left(80^{1}\right)$, absence of the postglenoid foramen $\left(123^{1}\right)$, glenoid cavity not concave but anteroposteriorly slanted $\left(133^{0}\right)$, posterior extension of the mandibular symphysis ending distally to the $\mathrm{p} 2\left(138^{1}\right), \mathrm{a}$ mandibular angle not ventrally extended $\left(143^{1}\right)$, absence of paraconule on the upper deciduous teeth $\left(172^{1}\right)$, and the presence of an endoparacrista on the upper deciduous teeth $\left(175^{1}\right)$ which is the only non-homoplastic character among those synapomorphies. 
It is worth noting that the genus Paralophiodon is polyphyletic in this topology.

Paralophiodon buxowillanum is the sister taxon of all other Lophiodon-Paralophiodon and $P$. leptorhynchum is found in a polytomy with $L$. remense from the Paris Basin and the Geiseltal. The polyphyly of the genus Paralophiodon in our topology is another argument for a critical reappraisal of the genus, already suggested by Holbrook (2009) and Godinot et al. (2018)

Protomoropus and Paleomoropus are placed as successive sister taxa to the Lophiodontidae and the family Eomoropidae appears paraphyletic on the strict consensus cladogram. Other eomoropids constitute a clade that is the sister taxon to the grouping of Protomoropus, Paleomoropus and Lophiodontidae. The clade gathering the Lophiodontidae and the paraphyletic Eomoropidae here corresponds to the Ancylopoda, as already supported by Hooker and Dashzeveg (2004) and which also contain the later Chalicotheriidae. The Ancylopoda clade is here supported by a Bremer index of 4 and by 6 unambiguous synapomorphies: presence of a diastema between P1 and P2 $\left(8^{1}\right)$; metacone of P3 more lingual than the paracone $\left(27^{1}\right)$; presence of a postprotocrista in P3 $\left(35^{1}\right)$, preprotocrista of the upper molars notched lingual to the paraconule $\left(63^{1}\right)$; flat metacone labially on M3 $\left(71^{0}\right)$; nasal notch positioned rostrally to the canine $\left(118^{0}\right)$; and one unambiguous non homoplasic character: absence of p1 $\left(82^{1}\right)$.

The node grouping Protomoropus, Paleomoropus and the Lophiodontidae is less supported but presents two unambiguous synapomorphies: labially flat metacone on upper premolars $\left(28^{0}\right)$ and on M1-M2 $\left(54^{0}\right)$. The presence of a metacone more labial on M3 than on M2 $\left(72^{0}\right)$ is an unambiguous synapomorphy of the clade gathering Paleomoropus and the Lophiodontidae.

The Ancylopoda and the Ceratomorpha, including Homogalax, are sister taxa and form the Tapiromorpha, sensu Hooker $(1984,1989)$. This clade is strongly supported with a Bremer index superior to 4 and by 11 non unambiguous synapomorphies: presence of a distinct parastyle on P2 $\left(10^{1}\right)$, high parastyle in P3-P4 $\left(25^{1}\right)$, quadrangular $\mathrm{P} 4\left(41^{1}\right)$, absence of paraconule on $\mathrm{P} 4\left(45^{1}\right)$, absence of the metaconule on $\mathrm{P} 4\left(46^{1}\right)$ connection between the postprotocrista and the 
endometacrista/ectoloph on P4 $\left(48^{1}\right)$, connection between the metaloph and the ectoloph on upper molars $\left(60^{1}\right)$, absence of posthypocristid on $\mathrm{p} 3-\mathrm{p} 4\left(87^{1}\right)$, presence of a distinct postorbital process on the jugal $\left(128^{1}\right)$, constant height of the mandible under the tooth row $\left(142^{1}\right)$ and presence of a tuber spinae $\left(145^{1}\right)$.

The analysis of the reduced matrix resulted in 252 most parsimonious trees of 495 steps. The consensus tree (SuppData 3, Fig. 4) presents an homoplasy index of 0.62, a re-scaled consistency index of 0.24 and a retention index of 0,62 . The nodes that are collapsed in the reduced topology are figured with an "*” on the topology of the extended matrix (Fig. 11). The phylogenetic relationships between the Hippomorpha are better resolved in this topology. However, the Bremer index for these nodes are weak (Bremer index=1). The nodes of the Tapiromorpha, the Ceratomorpha and the Ancylopoda are still well supported in the reduced topology with high Bremer index. The phylogenetic relations between the group of interest of the early lophiodontids and eomoropids are unchanged. However, the nodes between Ls. maurettei and the other Lophiodontidae, as well as the node between $L$. baroensis and the other Lophiodontinae collapse and the taxa are branched on a polytomy. The relationships among the more recent lophiodontids have also changed with the $L$. cuvieri from Jouy and the Geiseltal now being sister taxa.

\section{DISCUSSION}

\section{Reassessment of Ls. maurettei and Phylogenetic Implications}

The inclusion of the new material of Ls. maurettei considerably improves our understanding of the morphology of basal lophiodontids. Lophiaspis maurettei is now the best known perissodactyl from the early Ypresian of Europe, and the first one for which the cranium is documented. The new remains enlarge considerably the diagnosis of Ls. maurettei, document new characters absent in later lophiodontids, and reassess the importance of Ls maurettei as a key taxon to understand the phylogenetic relationships of lophiodontids within perissodactyls. 
Our phylogenetic results support the attribution of Ls. maurettei to the Lophiodontidae. This is consistent with the early assessment of Depéret (1910) and the phylogeny of Robinet et al. (2015). The Lophiodontidae, including Ls. maurettei, are nested within the Ancylopoda according to our analysis. This topology is consistent with those of Hooker and Dashzeveg (2004) and Bai et al., (2018). However, our topology differs from these previous studies by the monophyly of Lophiodontidae and by the position of Protomoropus as a stem lophiodontid rather than as the sister taxon of all other Ancylopoda on the "reduced" topology. This topology also contrasts with the phylogeny of Holbrook (2009) where Ls. maurettei was not included and which placed Lophiodon within the Ceratomorpha. Lophiaspis maurettei displays a morphology that is close to early eomoropids, notably with the presence of a diastema between P1-P2, the absence of $\mathrm{p} 1$ as well as the retention of a broad paraconule and postectometacristid on lower molars. These characters are absent in early Ceratomorpha. Furthermore, the dental similarities observed between the more recent Lophiodontinae and Ceratomorpha (e.g. molarized premolars in Chasmotherium; presence of an endoparacrista in Hyrachyus and loss of the paraconule on both taxa) are absent in early Lophiodontidae, and they appear as convergences between late diverging lophiodontids and ceratomorphs in the analysis.

The morphology of Ls. maurettei is relatively archaic for a lophiodontid, as it retains several plesiomorphic characters absent in more recent taxa, notably the presence of P1. As the earliest diverging lophiodontid, Ls. maurettei does not present yet the evolutionary trends observed in later diverging members of this family. Indeed, the premolars of Ls. maurettei are not molarized, and most of the specimens display a sharp postprotocrista, which is only present in early lophiodontinae (Checa Soler, 1997; Robinet et al., 2015). The morphology of dp2 and dp3 is simple and less molarized than in more recent taxa (Butler, 1952). In addition, the upper molars of Ls. maurettei bear a broad paraconule with a notched preprotocrista, whereas the paraconule becomes smaller and disappears during the evolutionary history of later diverging lophiodontids (Depéret, 1910; Robinet 
et al., 2015). Furthermore, the molars lack an ectostyle and most of the specimens also lack an endoparacrista, whereas these features are characteristic in the later diverging genus Lophiodon (Savage et al., 1966). Lophiaspis also retains the postglenoid foramen, like in E. laboriense (Robinet et al., 2015), this feature being absent in more recent taxa (Holbrook, 2009). The glenoid cavity of Ls. maurettei is also more concave and less extended anteriorly than in Eolophiodon and Lophiodon (Holbrook, 2009; Robinet et al., 2015). The dental polymorphism observed in Ls. maurettei is similar to that found in other Lophiodontidae (Sudre, 1971; Godinot et al., 2018; Vautrin et al., 2019). The size differences between the canine of AMU13084, the mandible figured by Repelin (1930) and MHN.AIX.PV.2018.26.1 are not surprising as a strong sexual dimorphism is present in many lophiodontids (Depéret, 1907; Godinot et al., 2018; Vautrin et al., 2019). We tentatively identify AMU13084 and the mandible of Repelin as females and MHN.AIX.PV.2018.26.1, MHN.AIX.PV.2017.6.1.2 and MHN.AIX.PV.2017.6.4 as males. In addition, it is worth noting that the size differences are greater in Ls. maurettei (Tab. 4, Fig. 7) than in E. laboriense and in the other lophiodontids (Vautrin et al., 2019).

\section{Robustness of the Phylogenetic Hypotheses among Early Diverging Perissodactyls}

Our alternative tests showed that only a few nodes of our phylogenetic reconstructions are sensitive to potential covariations between characters as they collapsed after the analysis of the reduced matrix (see Material and Methods, Results, and SuppData 2). The collapsing nodes correspond mainly to the early radiation of lophiodontids and to the radiation of ParalophiodonLophiodon. This result is not a surprise as these taxa present a high level of dental polymorphism, even emphasised by the fusion of characters from successive loci in the reduced matrix (see below). Furthermore Lophiodon-Paralophiodon species are distinguished by characters mostly linked to the molarisation of the premolars. Fusion of characters from upper and lower premolars could downweigh differences between taxa with different degrees of molarisation between the P3-P4 or 
p3-p4. However, overall the phylogenetic relationships within the lophiodontids remain similar with the topology from the extended matrix. Finally, the relationships between the early hippomophs are better resolved, but remain weakly supported.

Our analyses therefore suggested rather small effects of potential covariations among successive teeth on the phylogenetic reconstructions of early diverging perissodactyls. Yet, more research on the correlated patterns of dental variation in the group remains desirable. For the construction of the reduced matrix, we have used a rather simplistic approach by merging into a single character the potentially covarying traits on successive molars or premolars (see Material and Methods). When the configuration was different among successive loci for a given taxon, the merged character was scored as polymorphic for this taxon in the reduced matrix. This methodology, which is not very satisfactory (see Billet and Bardin, 2019), was only used to estimate the potential effects of covariation as a complementary test to the extended matrix. In addition, it must be emphasized that dental covariations may not only concern serial features on successive teeth, but also different structures on a same tooth (e.g., Kangas et al., 2004). Future systematic works on early diverging perissodactyls should therefore concentrate their efforts on unraveling patterns of dental covariation within the group and on building adapted character models (Billet and Bardin, 2019).

Other issues potentially affecting the robustness of the phylogenetic results among the group concern the large amount of polymorphic dental characters (SuppData 1) while some taxa are scored based on a single specimen. This can cause differential sampling of morphs among polymorphic taxa and affect the topology of the reconstructed trees (Watanabe, 2016). This is particularly the case for lophiodontids, which present high dental polymorphism in the species with numerous specimens (Sudre, 1971; Godinot et al., 2018; Vautrin et al., 2019) and where more studies on intraspecific variation are needed. The very large proportion of dental characters in the matrix is also an aspect that requires further improvement (see Sansom et al., 2017), possibly with 
the addition of more cranial and postcranial characters and the study of internal cranial structures (e.g., Danilo et al., 2015).

\section{Paleobiogeography}

The phylogenetic topologies suggest that lophiodontids took their origin from a chalicotherioid stock as proposed by Hooker and Dashzeveg (2004) and Bai et al., (2018). The locality of Palette is considered close to the MP7 (Marandat et al., 2012), the separation between the lophiodontids and the Protomoropus-Paleomoropus-like eomoropids may have occurred during the late Paleocene or the earliest Eocene, shortly after the separation between Ancylopoda and Ceratomorpha (Bai et al., 2018).

Hooker and Dashzeveg (2004) proposed that Lophiodontidae derived from paleomoropidlike chalicotheres in North America, and then dispersed through Europe via the Atlantic-Greenland land Bridge. However, lophiodontids are absent from the well documented Eocene fossil record of North America, as well as from North European localities dated from the early Ypresian (MP7). At that time, Lophiaspis maurettei is confined to Southern Europe. During the early Ypresian, mammalian faunas from Southwestern Europe were characterized by a strong provincialism with a high number of endemic species (Marandat et al., 2012; Solé et al., 2014, 2017). The restricted geographical distribution of the earliest and basal-most lophiodontids exemplifies their Southern European endemism at the MP7. Their absence from Northern European deposits seems incongruent with a North American origin for the family, as most of faunal exchanges between North America and Europe passed by Northern Europe and the Atlantic-Greenland land Bridge (Smith et al., 2006; Bai et al., 2018).

The Ancylopoda are absent from Europe before the appearance of lophiodontids. Lophiodontids could have emerged from an eomoropid stock from Central Asia before the dispersal of Paleomoropus to North America and dispersed through Europe. Indeed, Ls. maurettei from 
Palette and Paleomoropus are morphologically and phylogenetically close to Protomoropus gabuniai from Tsagan Kushu, Mongolia. In addition, the faunal resemblances between these early Eocene localities of Southern France and Mongolia have already been noticed in other ungulates. Lessnessina praecipuus and Lessnessina packmani are two species belonging to the hyopsodontid ungulates known from the $\sim$ MP7 localities of Palette (France; Godinot et al., 1987), Le Clot (France; Marandat et al., 2012) and Abbey Wood (England; Hooker, 1979). The closest relative of these two European species is Lessnessina kushuensis from the early Bumbanian of Tsagan Kushu, Mongolia (Hooker and Dashzeveg, 2003; Marandat et al., 2012), a locality which interestingly also yielded remains of Protomoropus gabunai. Lessnessina kushuensis is less derived than the two European species and a dispersion from a Central Asian to Europe across the Turgai strait has been proposed for this genus (Hooker and Dashzeveg, 2003). Similar dispersion from Asia to Europe during the early Eocene has also been proposed for the isectolophid Chowliia (Bronnert et al., 2018b), equoids (Godinot and Lapparent De Broin, 2003; Hooker and Dashzeveg, 2003) and for adapid (Godinot and Lapparent De Broin, 2003) and omomyid (Smith et al., 2006) primates. During the Thanetian and the early Ypresian four marine regressions have been documented between 57.2 and 54.5 Ma (Iakovleva et al., 2001). The Turgai strait would have been narrower, or dried out during these low sea events, thus favoring the dispersal of terrestrial mammals (Godinot and Lapparent De Broin, 2003; Hooker and Dashzeveg, 2003), including the lophiodontids.

\section{ACKNOWLEDGMENTS}

This paper is dedicated to the memory of Henri-Pierre Labarrère, an amateur paleontologist who dedicated part of his life to the study of lophiodontids. We first want to thank the Rougier family, owner of the site, who kindly provided access, help and support for paleontological research on the locality of Palette. Preparation of several specimens was done by E. Zoukouba (Ecole 
Pratique des Hautes Etudes, Paris) R. Vacant (Museum National d'Histoire Naturelle) A.L Charruault (Institut des Sciences de l'Evolution de Montpellier). 3D data acquisitions were performed using the $\mu \mathrm{CT}$ facilities of the MRI platform member of the national infrastructure France-BioImaging supported by the French National Research Agency (ANR-10-INBS-04, «Investments for the future»), and of the Labex CEMEB (ANR-10-LABX-0004) and NUMEV (ANR-10-LABX-0020). Recent excavations at Palette and scans of the material were funded thanks to the Actions Transversales du Muséum (ATM Palette, MNHN funding). We thank E. Turini and L. Mohring for their precious help during the excavations. We are indebted to S. Jiquel (Université de Montpellier, France), C. Argot (Muséum national d'Histoire naturelle, Paris, France), E. Robert (Université Claude Bernard Lyon 1, France), O. Wings (GeiseltalMuseum, Halle, Germany), L. Costeur (Naturhistorisches Museum Basel, Switzerland) and J. Galindo (Institut Català de Paleontologia Miquel Crusafont, Sabadell, Spain) who gave us access to the collection in their care.

\section{REFERENCES}

Bai, B., Y. Wang, and J. Meng. 2010. New Craniodental Materials of Litolophus gobiensis (Perissodactyla, “ Eomoropidae ”) from Inner Mongolia, China, and Phylogenetic Analyses of Eocene Chalicotheres. American Museum Novitates 3688:1-27.

Bai, B., Y. Wang, and J. Meng. 2011. Early Eocene Chalicothere Litolophus with hoof-like unguals. Journal of Vertebrate Paleontology 31:1387-1391.

Bai, B., Y. Wang, and J. Meng. 2018. The divergence and dispersal of early perissodactyls as evidenced by early Eocene equids from Asia. Communications Biology 1:1-10.

Bai, B., Y. Wang, H. Wang, and L. Holbrook. 2017. Osteology of the middle Eocene Ceratomorph Hyrachyus modestus (Mammalia, Perissodactyla). Bulletin of the American Museum of Natural History 413:1-68. 
Billet, G., and J. Bardin. 2019. Serial Homology and Correlated Characters in Morphological Phylogenetics : Modeling the Evolution of Dental Crests in Placentals. Systematic Biology 68:267-280.

Bronnert, C., E. Gheerbrant, M. Godinot, and G. Métais. 2018a. A primitive perissodactyl (Mammalia) from the early Eocene of Le Quesnoy (MP7, France). Historical Biology 1-13.

Bronnert, C., E. Gheerbrant, M. Godinot, and G. Metais. 2018b. First European 'Isectolophidae' (Mammalia, Perissodactyla): Chowliia europea, sp . nov., from the lower Eocene of Le Quesnoy, France. Journal of Vertebrate Paleontology 38:1-9.

Butler, P. M. 1952. The milk molars of Perissodactyla with remarks on molar occlusion. Proceedings of the Zoological Society of London 4:777-817.

Checa Soler, L. 1997. [Los Perisodactilos (Ungulata, Mammalia) del Eoceno Catalan]. Paleontologia i Evolució 149-234. [Spanish]

Cojan, I., M. G. Moreau, and L. E. Stott. 2000. Stable carbon isotope stratigraphy of the Paleogene pedogenic series of southern France as a basis for continental-marine correlation. Geology 28:259-262.

Colbert, M. W. 1934. Chalicotheres from Mongolia and China in The American Museum. Bulletin of the American Museum of Natural History LXVII:1-387.

Cooper, L. N., E. R. Seiffert, M. Clementz, S. I. Madar, S. Bajpai, S. T. Hussain, and J. G. M. Thewissen. 2014. Anthracobunids from the Middle Eocene of India and Pakistan Are Stem Perissodactyls. PloS ONE 9:1-15.

Cope, E. D. 1889. The vertebrata of the Swift Current River, II. American Naturalist 23:151-155.

Cuvier, G. 1822. [Recherches Sur Les Ossemens Fossiles (Nouvelle Éditions), Volume 2, Part 1] (G. Dufour and E. D’Ocagne (eds.)). Paris, france, 604 pp. [French] 
Danilo, L., J. A. Remy, M. Vianey-Liaud, S. Mérigeaud, and F. Lihoreau. 2015. Intraspecific Variation of Endocranial Structures in Extant Equus: A Prelude to Endocranial Studies in Fossil Equoids. Journal of Mammalian Evolution 22:561-582.

Dedieu, P. 1977. [Sur la Systematique des Tapiroidea (Mammalia) de l'Éocène européen]. Comptes Rendus de 1'Académie Des Sciences de Paris 284:2119-2222. [French]

Depéret, C. 1907. [Études paléontologiques sur les Lophiodon du Minervois]. Archives Du Muséum d'Histoire Naturelle de Lyon 9:1-48. [French]

Depéret, C. 1910. [Études sur la famille des Lophiodontidés]. Bulletin de La Société Géologique de France 558-577.

Estravis, C. 1992. [Estudo dos mamiferos do Eocénico inferior de Silveirinha (Baixo Mondego)]. Lisboa, 248 pp. [Portuguese]

Filhol, H. 1888. [Étude sur les vertébrés fossiles d'Issel (Aude)]. Mémoires de La Société Géologique de France 1-188. [French]

Fischer, V. K. 1977. [Neue Funde von Rhinocerolophiodon (n. gen.), Lophiodon und Hyrachyus (Ceratomorpha, Perissodactyla, Mammalia) aus dem Eozän des Geiseltals bei Halle 2]. Zeitschrift für geologische Wissenschaften, Berlin 5:1129-1152. [German]

Foley, N. M., M. S. Springer, and E. C. Teeling. 2016. Mammal madness: is the mammal tree of life not yet resolved? Philosophical Transactions B 1-11.

Franzen, J. L. 1990. [Hallensia (Mammalia, Perissodactyla) aus Messel und dem Pariser Becken sowie Nachträge aus dem Geiseltal]. Bulletin de l'Institut Royal Des Sciences Naturelles de Belgique 60:175-201. [German]

Franzen, J. L., and H. Haubold. 1986. Ein neuer condylarthre und ein tillodontier (Mammalia) aus dem Mitteleozän des Geiseltales. Paleovertebrata 16:35-53. 
Gingerich, P. D. 1989. New earliest Wasatchian mammalian fauna from the Eocene of Northwestern Wyoming: Composition and diversity in a rarely sampled high-floodplain assemblage. Papers on Paleontology 28:1-97.

Gingerich, P. D. 2006. Environment and evolution through the Paleocene - Eocene thermal maximum. Trends in Ecology \& Evolution 21:246-253.

Gilles, T. 1872. Arrangement of the families of mammals with analytical tables. Smithsonian Miscellaneous Collections 11:1-98.

Godinot, M. 1981. [Les mammifères de Rians (Eocène inférieur, Provence)]. Paleovertebrata 10:43-126. [French]

Godinot, M., and F. Lapparent De Broin. 2003. Arguments for a mammalian and reptilian dispersal from Asia to Europe during the Paleocene-Eocene boundary interval; pp. 255-276 in J. W. F. Reumer and W. Wessels (eds.), Distribution and migration of Tertiary mammals in Eurasia. A volume in Honour of Hans de Bruijn.

Godinot, M., J.-Y. Crochet, J. Hartenberger, B. Lange-Badré, D. E. Russell, and B. Sigé. 1987. [Nouvelles données sur les mammifères de Palette (Eocène inférieur, Provence)]. Münchner Geowissenschaftliche Abhandlungen A:273-288. [French]

Godinot, M., H. Labarrère, J. Erfurt, J. L. Franzen, B. Lange-Badré, F. Lapparent De Broin, and D. Vidalenc. 2018. [Un nouveau gisement à vertébrés éocènes, Rouzilhac (MP 10-11), dans la série molassique d'Issel (Aude, France)]. Revue de Paléobiologie, Genève 37:143-335. [French]

Haeckel, E. 1873. Natürliche Schöpfungsgeschichte. Vierte Auflage. Georg Reimer, Berlin, 688 pp. Hellmund, M. 2016. Tooth emergence and replacement in the European Hyrachyus minimus (Fischer, 1829) (Mammalia, Perissodactyla) from the Geiseltal Fossillagerstätte- a further example for “Schultz’s rule” in ungulates. N. JB. Geol. Paläont. Abh 282:157-180. 
Holbrook, L. T. 2001. Comparative osteology of early Tertiary tapiromorphs ( Mammalia, Perissodactyla ). Zoological Journal of the Linnean Society 132:1-54.

Holbrook, L. T. 2009. Osteology of Lophiodon Cuvier, 1822 (Mammalia, Perissodactyla) and its Phylogenetic Implications. Journal of Vertebrate Paleontology 29:212-230.

Holbrook, L. 2014. The Identity and Homology of the Postprotocrista and its Role in Molarization of Upper Premolars of Perissodactyla ( Mammalia ). Journal of Mammalian Evolution.

Holbrook, L. T., and J. Lapergola. 2011. A new genus of perissodactyl (Mammalia) from the Bridgerian of Wyoming, with comments on basal perissodactyl phylogeny. Journal of Vertebrate Paleontology 31:895-901.

Hooker, J. J. 1979. Two new condylarths (Mammalia) from the early Eocene of southern England. Bulletin of the British Museum (Natural History), Geology Series 32:43-56.

Hooker, J. J. 1984. A primitive ceratomorph (Perissodactyla, Mammalia) from the early Tertiary of Europe. Zoological Journal of the Linnean Society 82:229-244.

Hooker, J. J. 1989. Character polarities in early Perissodactyls and their significance for Hyracotherium and infraordinal relationships; pp. 79-101 in D. R. Prothero and R. M. Schoch (eds.), The evolution of Perissodactyls, Oxford Uni. New York.

Hooker, J. J. 2010. The mammal fauna of the Blackheath Formation of Abbey Wood, London. Monograph of the Palaeontographical Society 164:1-162.

Hooker, J. J., and D. Dashzeveg. 2003. Evidence for direct mammalian faunal interchange between Europe and Asia near the Paleocene-Eocene boundary. Geological Society of America Special Paper 369:479-500.

Hooker, J. J., and D. Dashzeveg. 2004. The origin of Chalicotheres (Perissodactyla, Mammalia). Palaeontology 47:1363-1386. 
Iakovleva, A. I., H. Brinkhuis, and C. Cavagnetto. 2001. Late Palaeocene - Early Eocene dinoflagellate cysts from the Turgay Strait, Kazakhstan ; correlations across ancient seaways. Paleogeography, Paleoclimatology, Paleoecology 172:243-268.

Kangas, A. T., A. R. Evans, I. Thesleff, and J. Jernvall. 2004. Nonindependence of mammalian dental characters. Nature 432:11-14.

Lebrun, R. 2019. MorphoDig, an open-source 3D freeware dedicated to biology IPC5, Paris, France. Version 1.4. .

Maddison, and Maddison. 2015. Mesquite: a modular system for evolutionary analysis. Version 3.04. http://www.mesquiteproject.org. .

Marandat, B., S. Adnet, L. Marivaux, A. Martinez, M. Vianey-Liaud, and R. Tabuce. 2012. A new mammalian fauna from the earliest Eocene (Ilerdian) of the Corbières (Southern France): palaeobiogeographical implications. Swiss Journal of Geosciences 105:417-434.

McKenna, M. C., M. Chow, S. Ting, and Z.-X. Luo. 1989. Radinskya yupingae, a perissodactyl-like mammal from the late Paleocene of southern China; pp. 24-36 in D. R. Prothero and R. M. Schoch (eds.), The Evolution of Perissodactyls., Oxford Uni. New York.

Meredith, R. W., J. E. Janec, J. Gatesy, O. A. Ryder, C. A. Fisher, E. C. Teeling, A. Goodbla, E. Eizirik, T. L. L. Simão, T. Stadler, D. L. Rabosky, R. L. Honeycutt, J. J. Flynn, C. M. Ingram, C. Steiner, T. L. Williams, T. J. Robinson, A. Burk-herrick, M. Westerman, N. A. Ayoub, M. S. Springer, and W. J. Murphy. 2011. Impacts of the Cretaceous Terrestrial Revolution and KPg Extinction on Mammal Diversification. Science 334:521-525.

Missiaen, P., F. Quesnel, C. Dupuis, J. Storme, and T. Smith. 2013. The earliest Eocene mammal fauna of the Erquelinnes Sand Member near the French-Belgian border. Geologica Belgica $16: 262-273$. 
Osborn, H. F. 1913. Eomoropus, an American Eocene Chalicothere. Bulletin of the American Museum of Natural History 32:261-274.

Owen, R. 1848. Description of teeth and portions of jaws of two extinct Anthracotherioid quadrupeds (Hyopotamus vectianus and Hyop. bovinus) discovered by the Marchioness of Hastings in the Eocene deposits on the NW coast of the Isle of Wight: with an attempt to develop. Quarterly Journal of the Geological Society of London 4:103-401.

Quinet, G. E., and W. Verlinden. 1970. [Sur l'Hyracotherium d'Erquelinnes (Jeumont)]. Bulletin de l'Institut Royal de Sciences Naturelles de Belgique 46:1-10. [French]

Radinsky, L. 1963. Origin and early evolution of North American Tapiroidea. Peabody Museum of Natural History Yale University Bulletin 17:1-106.

Radinsky, L. B. 1964. Paleomoropus, a New Early Eocene Chalicothere (Mammalia, Perissodactyla), and a Revision of Eocene Chalicotheres. American Museum Novitates 2179:1-28.

Radinsky, L. B. 1965. Evolution of the Tapiroid Skeleton from Heptodon to Tapirus. Bulletin of the Museum of Comparative Zoology 134:69-106.

Radinsky, L. B. 1969. The early evolution of the Perissodactyla. Evolution 23:308-328.

Remy, J. A., J.-J. Jaeger, Y. Chaimanee, A. N. Soe, L. Marivaux, J. Sudre, S. Thura Tun, B. Marandat, and E. Dewaele. 2005. A new Chalicothere from the Pondaung Formation ( late Middle Eocene of Myanmar ). Comptes Rendus - Palevol 4:341-349.

Remy, J. A., G. Krasovec, E. Lopez, B. Marandat, et F. Lihoreau. 2019. The Palaeotheriidae (Equoidea, Perissodactyla, Mammalia) from the Eocene fauna of Aumelas (Hérault department, France). Geodiversitas 41:525-585. 
Repelin, J. 1930. [Description Géologique Succinte Du Département Des Bouches-Du-Rhône], Société an. Marseille, 1-256 pp. [French]

Robinet, C., J. A. Rémy, Y. Laurent, L. Danilo, and F. Lihoreau. 2015. A new genus of Lophiodontidae (Perissodactyla, Mammalia) from the early Eocene of La Borie (Southern France) and the origin of the genus Lophiodon Cuvier, 1822. Geobios 48:25-38.

Roman, F., and N. Gennevaux. 1907. [Note sur un nouveau gisement de mammifères éocènes aux environs de Montpellier]. Bulletin de La Société Géologique de France 4:18-23. [French]

Rose, K. D., L. T. Holbrook, R. S. Rana, K. Kumar, K. E. Jones, H. E. Ahrens, P. Missiaen, A. Sahni, and T. Smith. 2014. Early Eocene fossils suggest that the mammalian order Perissodactyla originated in India. Nature Communications 5:1-9.

Sansom, R. S., M. A. Wills, and T. Williams. 2017. Dental Data Perform Relatively Poorly in Reconstructing Mammal Phylogenies : Morphological Partitions Evaluated with Molecular Benchmarks. Systematic Biology 66:813-822.

Savage, D. E., D. E. Russell, and P. Louis. 1966. Ceratomorpha and Ancylopoda (Perissodactyla) From the lower Eocene Paris basin, France. University of California Publication in Geologic Sciences $1-38$.

Smith, T., K. D. Rose, and P. D. Gingerich. 2006. Rapid Asia - Europe - North America geographic dispersal of earliest Eocene primate Teilhardina during the Paleocene - Eocene Thermal Maximum. PNAS 103:11223-11227.

Smith, T., K. Kumar, R. S. Rana, A. Folie, F. Solé, C. Noiret, T. Steeman, A. Sahni, and K. D. Rose. 2016. New early Eocene vertebrate assemblage from western India reveals a mixed fauna of European and Gondwana affinities. Geoscience Frontiers 7:969-1001. 
Solé, F., J. Falconnet, and L. Yves. 2014. New proviverrines (Hyaenodontida) from the early Eocene of Europe ; phylogeny and ecological evolution of the Proviverrinae. Zoological Journal of the Linnean Society 171:878-917.

Solé, F., M. Godinot, Y. Laurent, A. Galoyer, and T. Smith. 2017. The European Mesonychid Mammals : Phylogeny, Ecology, Biogeography, and Biochronology. Journal of Mammalian Evolution 1-41.

Steurbaut, E., R. Magioncalda, C. Dupuis, S. Van Simaeys, E. Roche, and M. Roche. 2003. Palynology, paleoenvironments, and organic carbon isotope evolution in lagoonal PaleoceneEocene boundary settings in North Belgium; pp. 291-317 in S. L. Wing, P. D. Gingerich, B. Schmitz, and E. Thomas (eds.), Causes and Consequences of Globally Warm Climates in the Early Paleogene, Geological. Boulder Colorado.

Sudre, J. 1971. [Étude de la variabilité chez Lophiodon lautricense Noulet]. Palaeovertebrata 4:6795. [French]

Swofford, D. L. 2003. PAUP*. Phylogenetic Analysis Using Parsimony (*and Other Methods).

Thewissen, J. G. M. 1990. Evolution of Paleocene and Eocene Phenacodontidae (Mammalia, Condylarthra). University of Michigan Papers on Paleontology 29:1-107.

Vautrin, Q., R. Tabuce, Y. Laurent, D. Vidalenc, and F. Lihoreau. 2019. Intraspecific variation of Eolophiodon laboriense, a basal Lophiodontidae (Mammalia, Perissodactyla) from the early Eocene of Southern France. Geobios 53:51-63.

Viret, J. 1958. Perissodactyla; pp. 368-475 in J. Piveteau (ed.), Traité de Paleontology, Tome IV, Masson \& C. Paris.

Watanabe, A. 2016. The impact of poor sampling of polymorphism on cladistic analysis. Cladistics $32: 317-334$. 
Wible, J. R., and G. W. Rougier. 2000. Cranial Anatomy of Kryptobaatar dashzevegi (Mammalia, Multituberculata), and its bearing on the Evolution of Mammalian Characters. Bulletin of the American Museum of Natural History 1-124.

Wiens, J. 1998. Testing Phylogenetic Methods with Tree Congruence: Phylogenetic Analysis of Polymorphic Morphological Characters in Phrynosomatid Lizards. Systematic Biology $47: 427-444$.

Wood, A. R., R. M. Bebej, C. L. Manz, D. L. Begun, and P. D. Gingerich. 2011. Postcranial Functional Morphology of Hyracotherium (Equidae, Perissodactyla) and Locomotion in the Earliest Horses. Journal of Mammalian Evolution 18:1-32.

Yans, J., B. Marandat, E. Masure, J. Serra-kiel, J. Schnyder, J. Storme, L. Marivaux, S. Adnet, M. Vianey-Liaud, and R. Tabuce. 2014. Refined bio- (benthic foraminifera, dinoflagellate cysts) and chemostratigraphy ( $\delta 13 \mathrm{C}$ org) of the earliest Eocene at Albas-Le Clot (Corbières, France): implications for mammalian biochronology in Southern Europe. Newsletters on Stratigraphy 47:331-353.

Wood, H. E. 1934. Revision of the Hyrachyidae. Bulletin of the American Museum of Natural History 67:181-290.

\section{FIGURE CAPTIONS}

FIGURE 1. Map of localities bearing Lophiaspis maurettei. MP7 localities are indicated by white circle, MP8+9 by grey circle and MP10 by black circle. Abbreviations: L, Les Salères; M, Mutigny ; P, Palette ; S, Silveirinha ; St, Saint-Pierre-des-Champs. [planned for column width]

FIGURE 2. Dental terminology on A: Upper premolar; B: Upper molar; C: p2; D: p3 and p4; E: lower molar. Abbreviations : EcHylid, Ectohypocristulid; EdMec, Endometacrista; EdPac, 
Endoparacrista; Edprc, Endoprotocrista; Hy, Hypocone; Hyd, Hypoconid; Hylid, Hypoconulid; Me, Metacone; Med, Metaconid; Pa, Paracone; Pad, Paraconid; Pal, Paraconule; Pas: Parastyle, PEcd, Preentoconid; PHyc, Prehypocrista; PHycd, Prehypocristid; PHylid, Prehypocristulid; PMec, Premetacrista; PMecd, Premetacristid; PoEcd, Postentocristid; PoectoMecd, Postectometaconid; PoectPrcd, Postectoprotocristid; PoHycd, Posthypocristid; PoHlid, Posthypocristulid; PoMec, Postmetacrista; PoMecd, Postmetacristid; PoPrcd, Postprotocristid, PoPac, Postparacrista; PoPasc, Postparacristyle, PoPrc, Postprotocrista, PPac, Preparacrista; PPacd, Preparacristid; PPalc, Preparacristule; PPasc, Preparacristyle, PrPrcd, Preprotocristid; Pr, Protocone; Prd, Protoconid The junction of two cristae or cristids forms a loph or a lophid. The junction between the preprotocrista and the preparacristule forms the protoloph. The connection of the postprotocristid and the postmetacristid forms the protolophid, and the connection between the postentoconid and the posthypocristid form the hypolophid. The distolingual cusp of the upper molars is surrounded by cingulum but is named hypocone due to historical arguments. Modified from Vautrin et al., 2019 [Planned for 2/3 page width]

FIGURE 3. Cranium of Lophiaspis maurettei, MHN.AIX.PV.2017.6.1.1 A, dorsal view; B, ventral view; C, 3D reconstruction in dorsal view; D, 3D reconstruction in ventral view. Abbreviations: Ca, canine alveoli; Ma, external auditory meatus; Nc, nuchal crest; Ni, nasal incision; Oc, occipital condyles; Of, oval foramen; P1, first premolar; P, petrosal, Pac, posterior opening of the alisphenoid canal; Pf, Pyriform fenestra; Pfm, major palatine foramina; Pgf, postglenoid foramen; Pgp, postglenoid process; Pop, post-orbital process; Ptp, post-tympanic process; Sop, supraorbital foramen. Scale bar equals $10 \mathrm{~mm}$. [planned for page width]

FIGURE 4. 3D models of MHN.AIX.PV.2017.6.4. A, in dorsal view; B, in three quarter view; $\mathbf{C}$, in ventral view; D, in lateral view; Abbreviations: Ca, canine alveoli; Fr, frontal bone; Hf, 
hypoglossal foramen; La, lacrimal bone; Ma; maxillary bone; Na, nasal bone; Ni, nasal incision; Nu, nuchal crest; Of, oval foramen; P, petrosal; Pac, posterior opening of the alisphenoid canal; Pgf, postglenoid foramen; Pgp, postglenoid process; Pop, post-orbital process; Ptp, post-tympanic process. Scale bar equals $10 \mathrm{~mm}$. [Planned for page width]

FIGURE 5. Close-up of the basicranium of Lophiaspis maurettei, MHN.AIX.PV.2017.6.1.1

Abbreviations: Ecf, external aperture of the cochlear fossula; Fo, foramen ovale; Fv, fenestra vestibuli; Pf, pyriform fenestra; Pgf, postglenoid foramen; Pr, promontorium; Sff, secondary facial foramen; Smf, stapedius muscle fossa. Scale equals $10 \mathrm{~mm}$. [Planned for $2 / 3$ page width]

FIGURE 6. Mandibles of Lophiaspis maurettei from Palette. A, MHN.AIX.PV.2017.6.1.2 in lateral view; B, MHN.AIX.PV.2017.6.1 in occlusal view; C, 3D reconstruction of MHN.AIX.PV.2017.6.1 in lateral view; D, 3D reconstruction of MHN.AIX.PV.2017.6.1 in occlusal view; E, MHN.AIX.PV.2018.26.3 (Reversed) in lateral view; F, 3D reconstruction of MHN.AIX.PV.2018.26.3 (Reversed) with the mandibular angle re-positioned. Abbreviations: Cd, condylar process; $\mathbf{C p}$, coronoïd process; Fm, mental foramina; Im, incisura mandibulae; Iv, incisura vascularis. Scale bar equals $10 \mathrm{~mm}$. [Planned for page width]

FIGURE 7. Teeth of Lophiaspis maurettei from Palette and other localities. A, left tooth row from MHN.AIX.PV.2017.6.1.1 (P2-M3); B, 3D reconstruction of MHN.AIX.PV.2017.6.1.1; C, 3D reconstruction of FSL2084 (holotype); D, canine of AMU13084; E, canine of MHN.AIX.PV.2018.26.1; F, right M3 from Les Salères, IPS-5778; G, left M3 from Les Salères, IPS-5735; H, cranium of AMU13084 in lateral view; I, 3D model of right tooth row from MHN.AIX.PV.2017.6.1.2 (P2-M3); J, left m2 from Mutigny, cast of MNHN Louis 194Mu (Reversed); K, right p2-m2 of AMU20020; L, left molars of UM-SPC-1 (Reversed); M, schematic 
representation of UM-SPC-1 with damaged part figured in grey. Scale bar equals $10 \mathrm{~mm}$. [Planned for page width]

FIGURE 8. Deciduous teeth of lophiodontids. A, right DP4 of Lophiaspis maurettei from Palette (MHN.AIX.PV.2019.5.3); B, right DP4 of Eolophiodon laboriense, APSO.2007.SP2-126; C, right DP3 of E. laboriense, APSO.2007.SP2-140; D, right DP4 of Ls. maurettei from Silveirinha, SV3 337; E, right dp2-dp4 of Lophiaspis. maurettei, MHN.AIX.PV.2018.26.3; F, 3D model of MHN.AIX.PV.2010.26.3; G, left dp3-dp4 of Eolophiodon. laboriense, APSO.2007.Sp2-102; H, right DP2-DP4 of Lophiodon lautricense, UM RBS 1457; I, left dp2-dp4 of Lophiodon lautricense, UM-RBS-7378. Abbreviations: Ec, ectostyle; Ed, endoparacrista; P, paraconid, Pa, paraconule; Pe, preentocristid; Pme, postectometacristid; Pp, postprotocristid. Scale bar equals $10 \mathrm{~mm}$. [Planned for column width]

FIGURE 9. Post-cranial elements of Lophiaspis maurettei from Palette. A, scapula in lateral view, MHN.AIX.PV.2019.5.7; B, fragmentary innominate in lateral view, MHN.AIX.PV.2019.5.10; C, tibia in cranial view, MHN.AIX.PV.2019.5.8; D, third metatarsal in medial view, MHN AIX.PV.2017.6.5; E, third metatarsal in lateral view, MHN.AIX.PV.2017.6.5; F, third metatarsal in cranial view, MHN AIX.PV.2017.6.5; G, proximal phalanx in caudal view, MHN.AIX.PV.2019.5.11; H, proximal phalanx in cranial view, MHN.AIX.PV.2019.5.11; I, medial phalanx in caudal view, MHN.AIX.PV.2019.5.12; J, medial phalanx in cranial view; MHN.AIX.PV.2019.5.12. Abbreviations: ac, acromion; act, acetabulum; cp, coracoid process; ec, ectocuneiform facet; isf, infraspinous fossa; il, ilio-pectineal line; ml, malleolus; Mt I, articular facet for the metatarsal I; Mt II, articular facet for the metatarsal II; Mt IV, articular facet for the metatarsal IV; ssf, supraspinous fossa; tc; tibial crest. Scale bar equals10 mm. [Planned for 2/3 column width] 
FIGURE 10. Astragalus and calcaneum of Lophiaspis maurettei from Palette, MHN.AIX.PV.2019.5.9 and MHN.AIX.PV.2019.5.6. A, astragalus in cranial view; B, astragalus in caudal view; C, calcaneum in lateral view; D, calcaneum in cranial view. Abbreviations: af, astragalar facet; cf, cuboid facet; def, distal calcaneal facet; ef, ectal facet; nf, navicular facet; su, sustentaculum; suf, sustentacularum facet. Scale bar equals $10 \mathrm{~mm}$. [Planned for column width]

FIGURE 11. Strict consensus tree of the 1848 most parsimonious topologies obtained by heuristic search of the "extended matrix" in PAUP 4.0a162. Tree length $=859$ steps, $\mathbf{C I}=0.7, \mathbf{R I}=0.59$. The Bremer indexes are calculated for each node. Asterisk $\left(^{*}\right)$ symbolizes the collapsed nodes in the alternative topology. The position of the MP8+9 and MP10 follow Yans et al., 2014; Noiret et al., 2016. The temporal distribution of the two Lophiodontidae from the "Minervois", Ls. occitanicus and P. leptorhynchum are represented as dotted lines after the MP11 as the need of a revision of the age of the reference locality of the MP15 has been pointed out recently (Godinot et al., 2018, Rémy et al., 2019). [Planned for page width]

Submitted July 23, 2019; revisions received Month DD, YYYY; accepted Month DD, YYYY 
TABLE 1. List of the specimens included in this study.

\begin{tabular}{|c|c|c|c|}
\hline Locality & Specimen number & Nature of the specimen & Taxa \\
\hline Palette & UCBL-FSL 2084 & Palate with teeth row (Holotype, Depéret 1910) & Lophiaspis maurettei \\
\hline Palette & MHN.AIX.PV.2017.6.1.1 & Cranium & Lophiaspis maurettei \\
\hline Palette & MHN.AIX.PV.2017.6.1.2 & Mandible & Lophiaspis maurettei \\
\hline Palette & MHN.AIX.PV.2017.6.4 & Cranium in block & Lophiaspis maurettei \\
\hline Palette & MHN.AIX.PV.2017.6.5 & Third metatarsus & Lophiaspis maurettei \\
\hline Palette & MHN.AIX.PV.2018.26.1 & Canine & Lophiaspis maurettei \\
\hline Palette & MHN.AIX.PV.2018.26.2 & M1 & Lophiaspis maurettei \\
\hline Palette & MHN.AIX.PV.2018.26.3 & Juvenile mandible & Lophiaspis maurettei \\
\hline Palette & MHN.AIX.PV.2019.5.1 & $\mathrm{P} 2-\mathrm{P} 4$ & Lophiaspis maurettei \\
\hline Palette & MHN.AIX.PV.2019.5.2 & P1 & Lophiaspis maurettei \\
\hline Palette & MHN.AIX.PV.2019.5.3 & DP4 & Lophiaspis maurettei \\
\hline Palette & MHN.AIX.PV.2019.5.4 & M1 & Lophiaspis maurettei \\
\hline Palette & MHN.AIX.PV.2019.5.5 & Astragalus & Lophiaspis maurettei \\
\hline Palette & MHN.AIX.PV.2019.5.6 & Calcaneum & Lophiaspis maurettei \\
\hline Palette & MHN.AIX.PV.2019.5.7 & Scapula & Lophiaspis maurettei \\
\hline Palette & MHN.AIX.PV.2019.5.8 & Tibia & Lophiaspis maurettei \\
\hline Palette & MHN.AIX.PV.2019.5.9 & Astragalus & Lophiaspis maurettei \\
\hline Palette & MHN.AIX.PV.2019.5.10 & Innominate & Lophiaspis maurettei \\
\hline Palette & MHN.AIX.PV.2019.5.11 & Proximal phalange & Lophiaspis maurettei \\
\hline Palette & MHN.AIX.PV.2019.5.12 & Medial phalange & Lophiaspis maurettei \\
\hline Palette & AMU13084 & Premaxillar and maxillar. I3-M2 & Lophiaspis maurettei \\
\hline Palettte & AMU70397 & P2-P4 & Lophiaspis maurettei \\
\hline Palette & AMU200196 & $\mathrm{P} 1$ \&P2 & Lophiaspis maurettei \\
\hline Palette & AMU20019 & Cranium & Lophiaspis maurettei \\
\hline Palette & AMU20020 & Mandible i1-m2 & Lophiaspis maurettei \\
\hline Saint-Pierre-des-Champs & SPC-1 & $\mathrm{m} 1 ?$ & Lophiaspis? maurettei \\
\hline Mutigny & MNHN.F.MU-12299 & P4 & cf. Lophiaspis mauretter \\
\hline Mutigny & MNHN.F.MU-194-L & $\mathrm{m} 2$ & cf. Lophiaspis maurette \\
\hline Mutigny & MNHN.F.MU-195-L & P4 & cf. Lophiaspis maurette \\
\hline Mutigny & UCMP 63667 & M2 & cf. Lophiaspis maurette \\
\hline Mutigny & UCMP 66353 & $\mathrm{p} 4$ & cf. Lophiaspis maurette \\
\hline Mutigny & UCMP 68037 & $\mathrm{~m} 3$ & cf. Lophiaspis maurette \\
\hline Les Saleres & IPS-5778 & M3 & Lophiodon sp. \\
\hline Les Saleres & IPS-5735 & M3 & Lophiodon sp. \\
\hline Silveirinha & SV3-337 & DP4 & Lophiaspis maurettei \\
\hline
\end{tabular}


TABLE 3. Mandible measurements (in $\mathrm{mm}$ ) of Lophiaspis maurettei.

\begin{tabular}{|c|c|c|c|c|c|c|c|c|c|c|c|}
\hline Specimens & Age & Sex & $\mathrm{Hp} 2$ & $\mathrm{Hm}$ & DL & TRL & $\mathrm{L}$ & RS & DMA & WMA & PML \\
\hline $\begin{array}{l}\text { MHN.AIX. } \\
\text { PV.2017.6.1 }\end{array}$ & Adult & M & 40.3 & 45 & 35.8 & 70.1 & 199 & 11 & 90.6 & 79.8 & 66.3 \\
\hline $\begin{array}{l}\text { MHN.AIX. } \\
\text { PV.2018.26.3 }\end{array}$ & Juvenile & $?$ & 17 & 17.9 & 16.1 & - & 115.9 & - & 40.4 & 43.6 & 43.1 \\
\hline Repelin & Adult & $\mathrm{F}$ & - & 31.7 & 40.5 & - & - & - & - & - & - \\
\hline
\end{tabular}

Abbreviations: DL, diastema length; DMA, distal height of the mandibular angle; F, female; Hm, height under molar; Hp2, height under p2 or dp2; L, length of the mandible; M, male; PML, Posterior length of the mandibular angle; RS, retromolar space; TRL, teeth row length; WMA, width of the mandibular angle. 


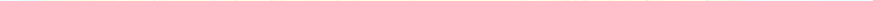


A
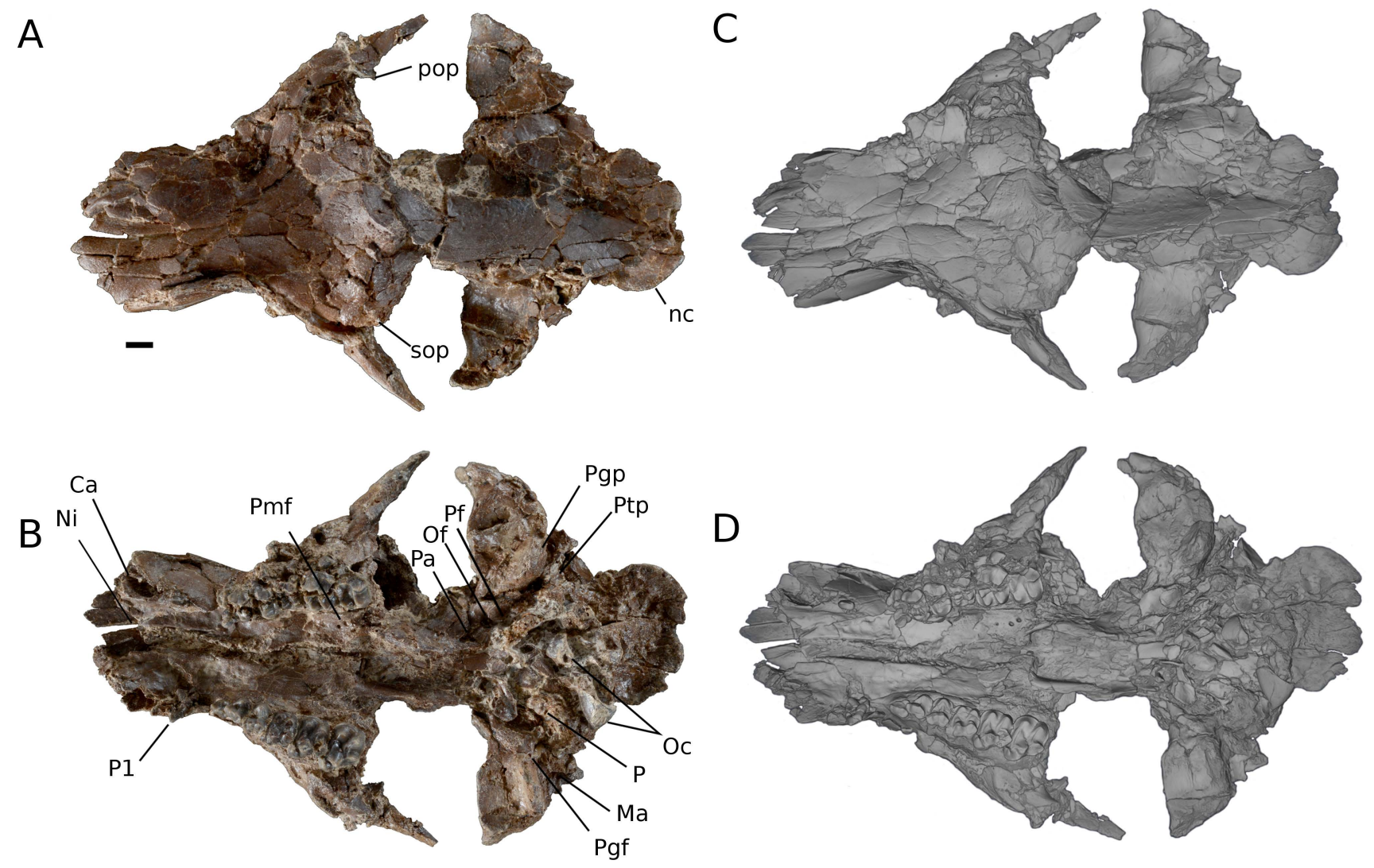

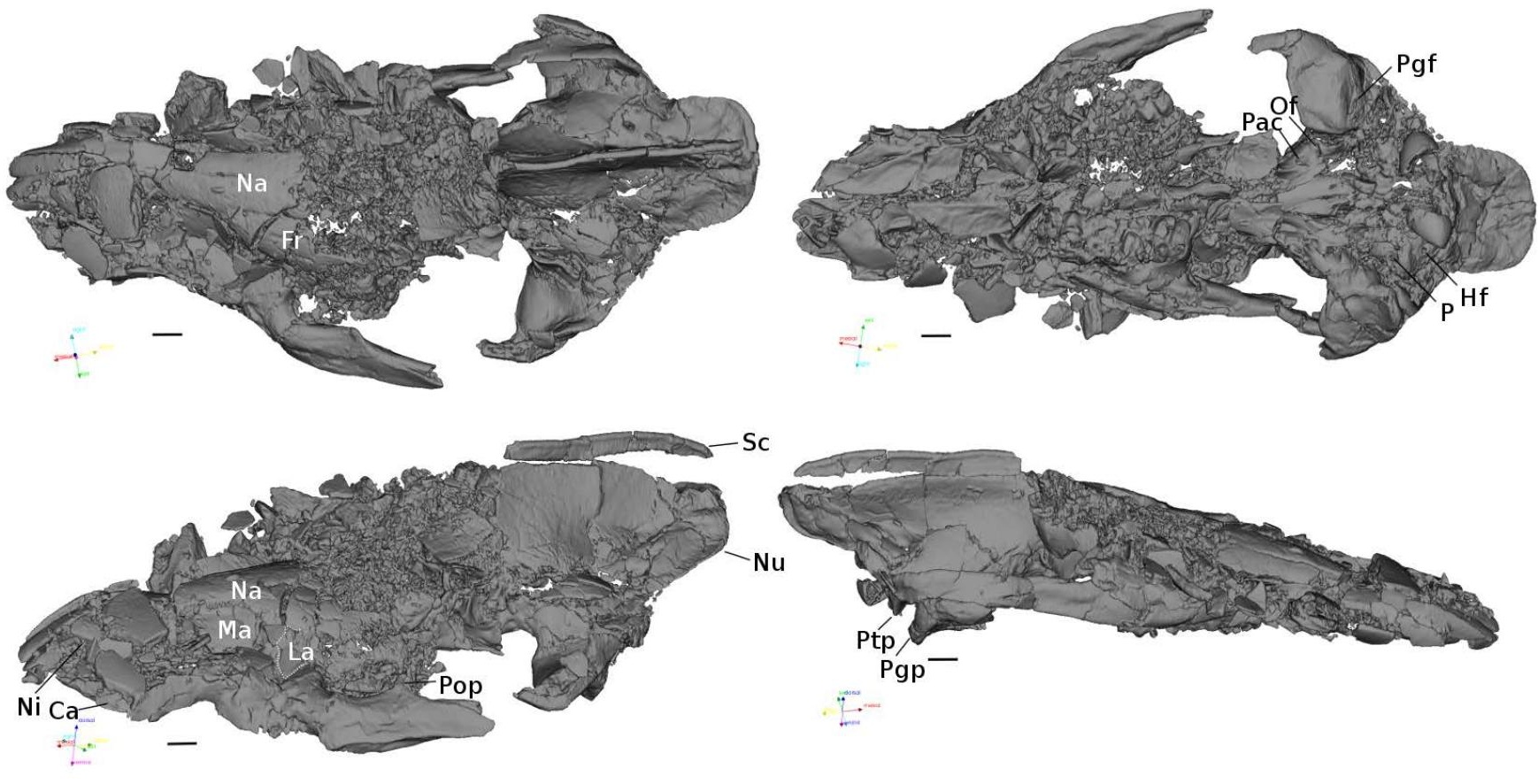


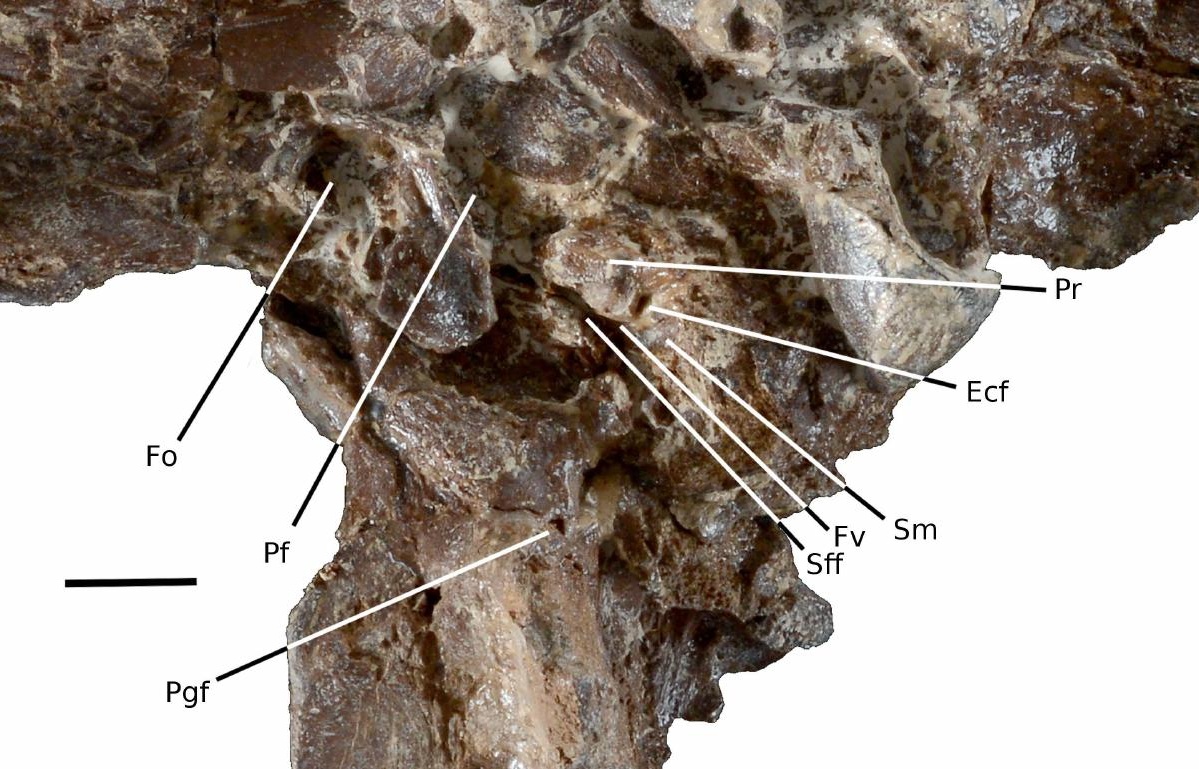


$-C p$

A

tomentan

Im

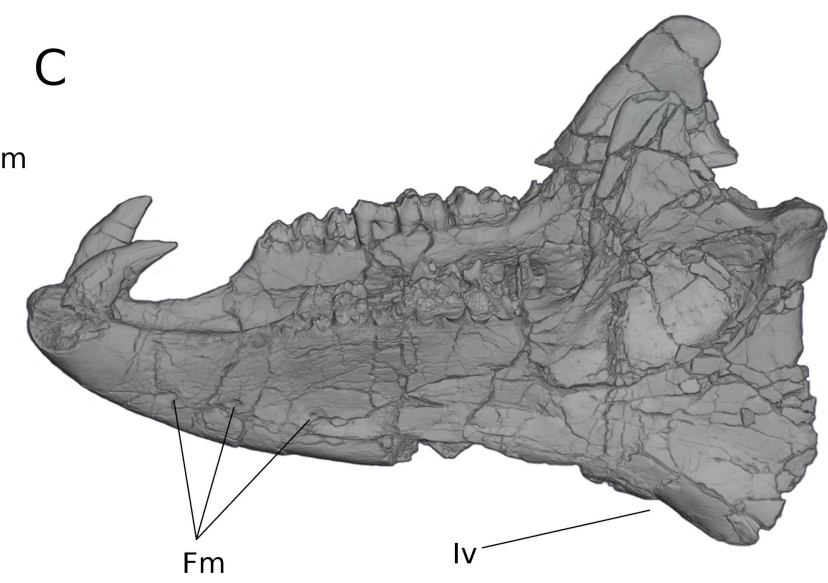

B

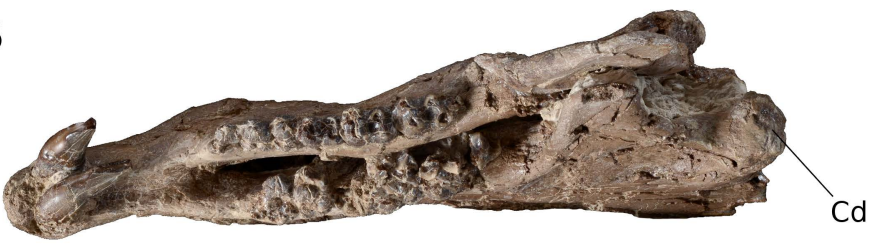

D

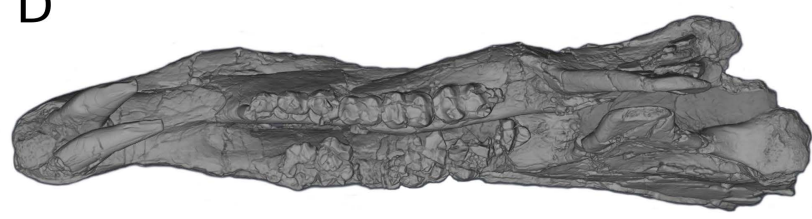

E
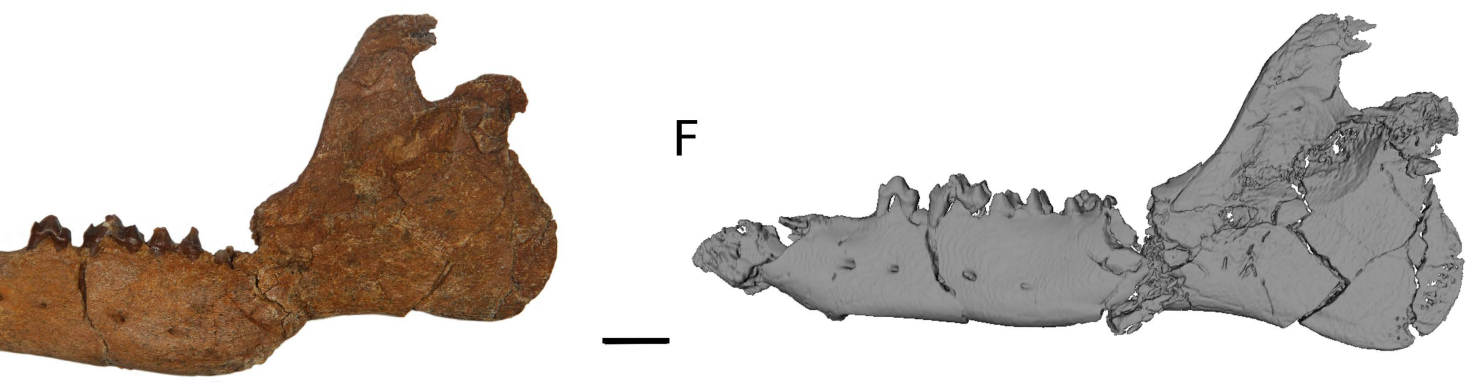
A

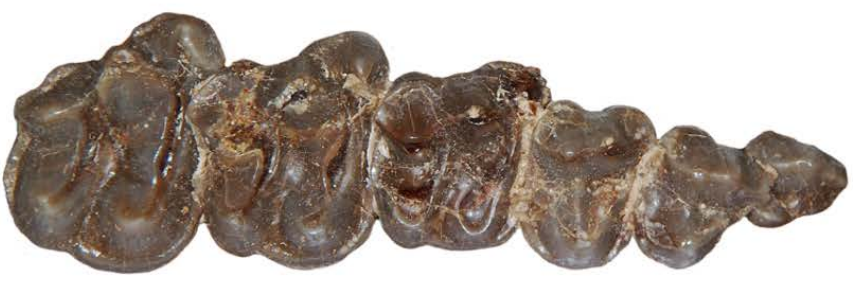

B

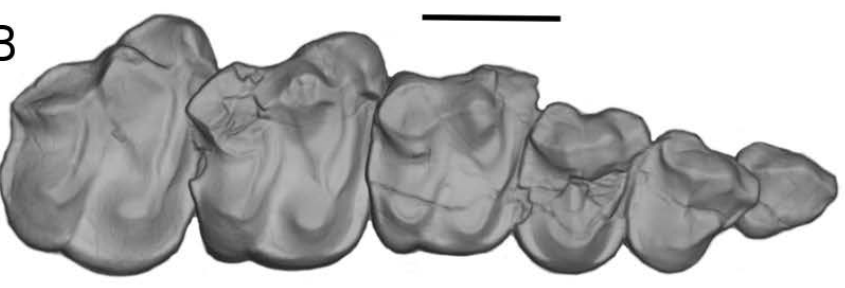

D

E
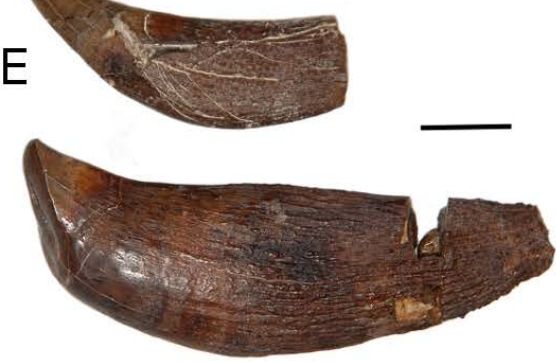

$\mathrm{F}$

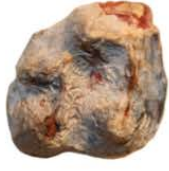

G

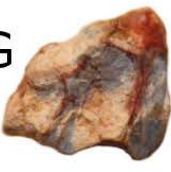

c
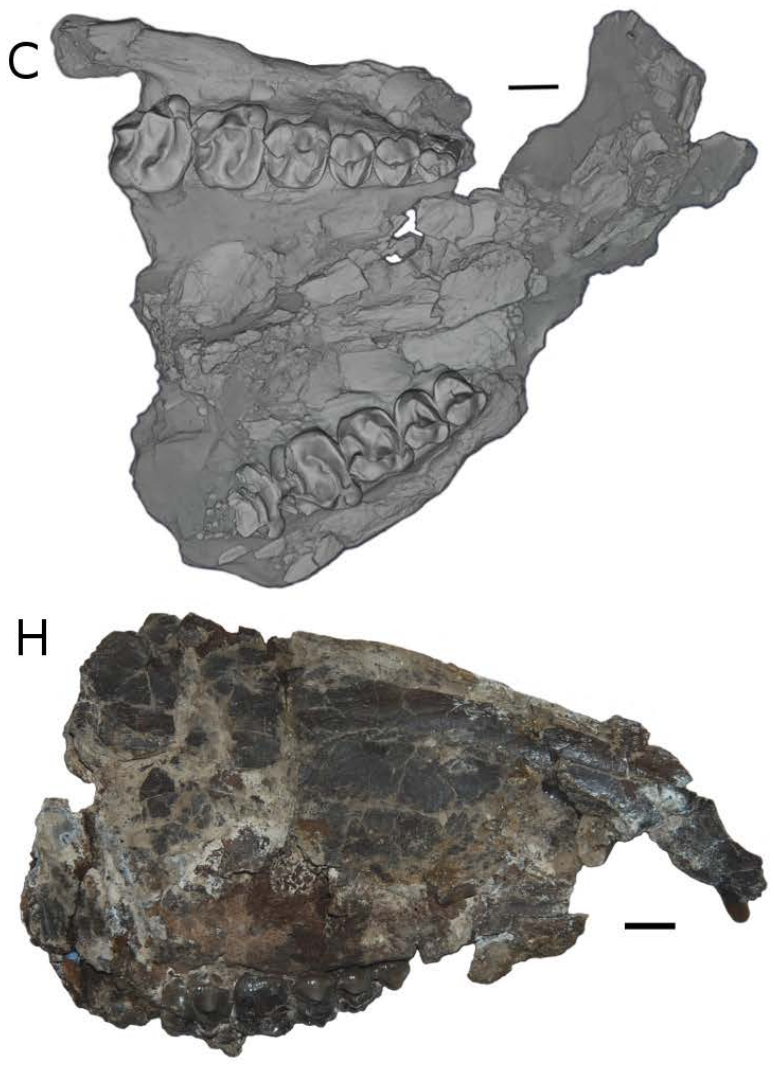

1 

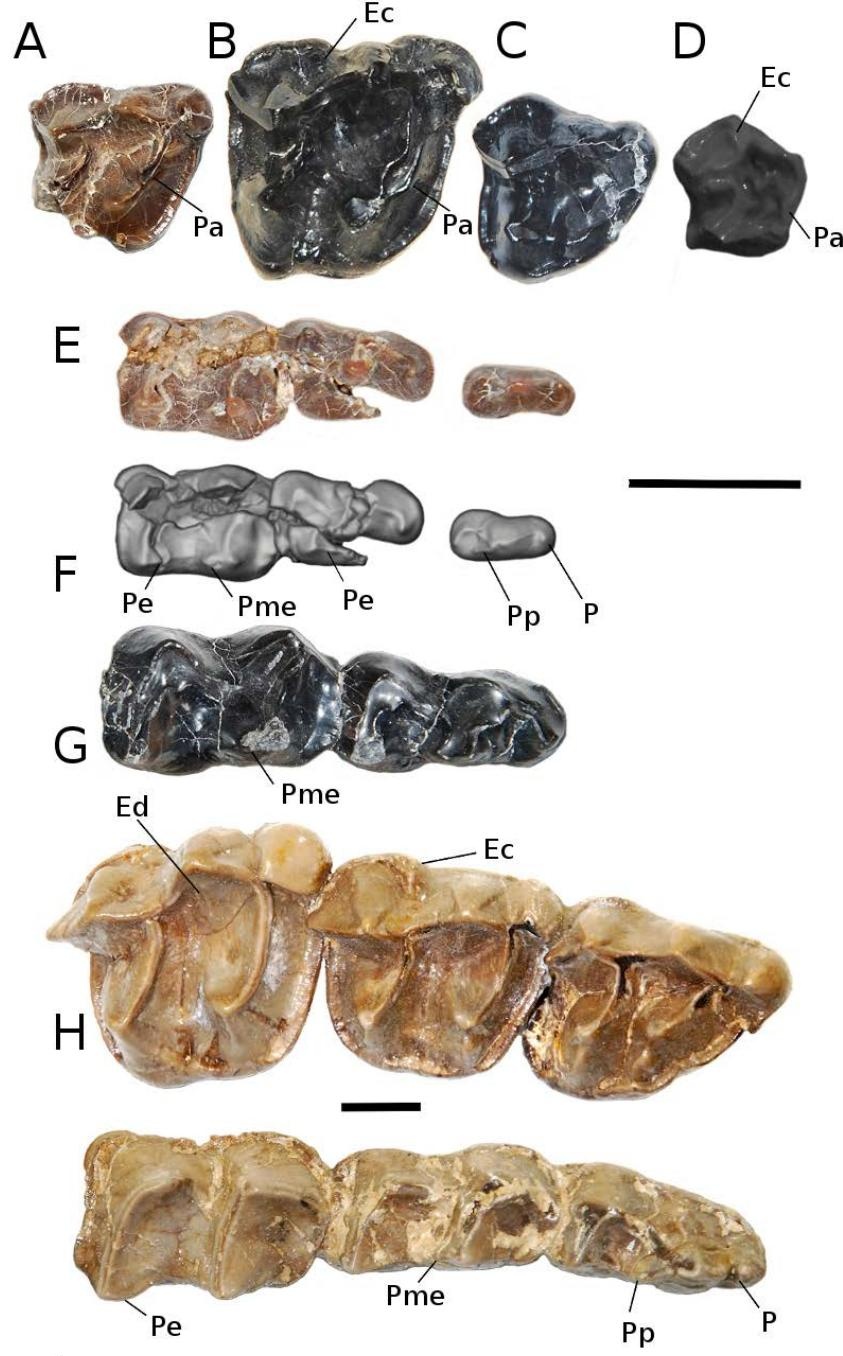


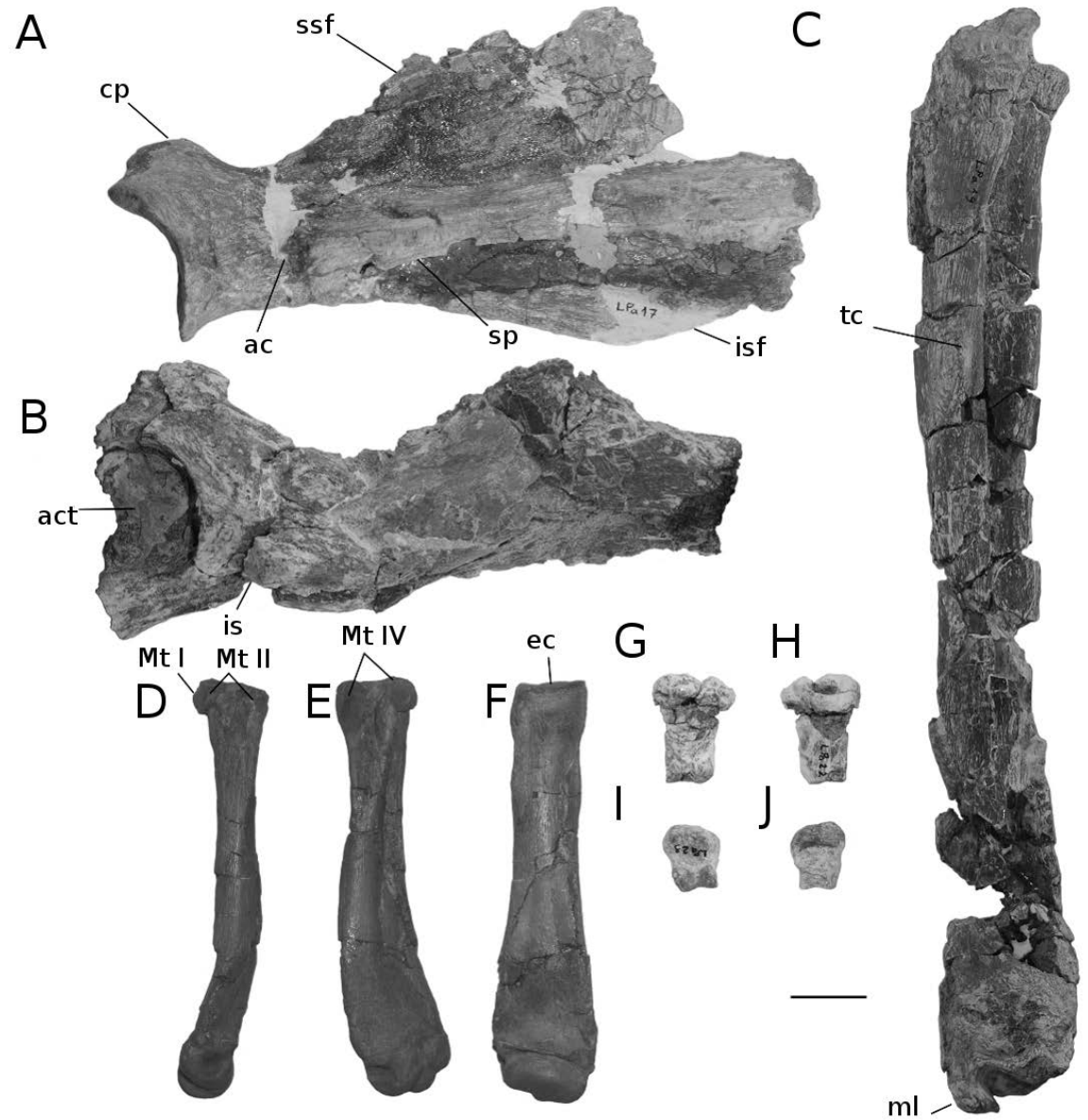


A

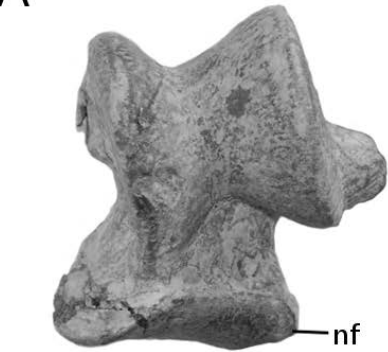

B

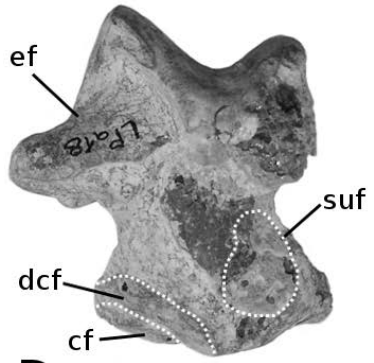

C

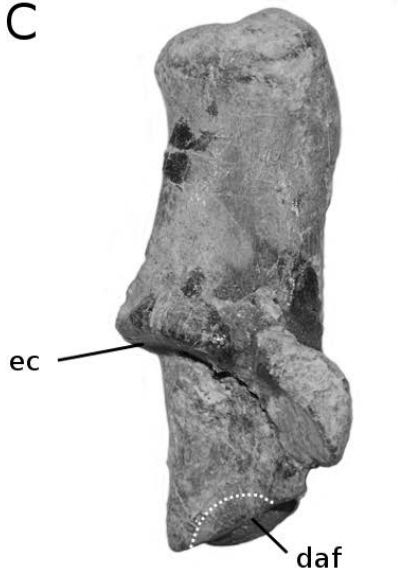

D

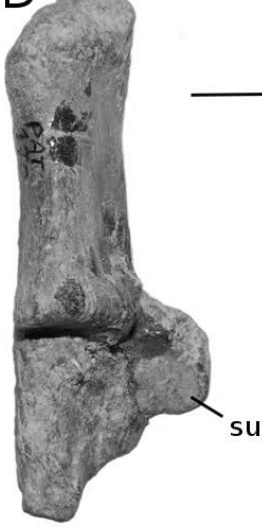




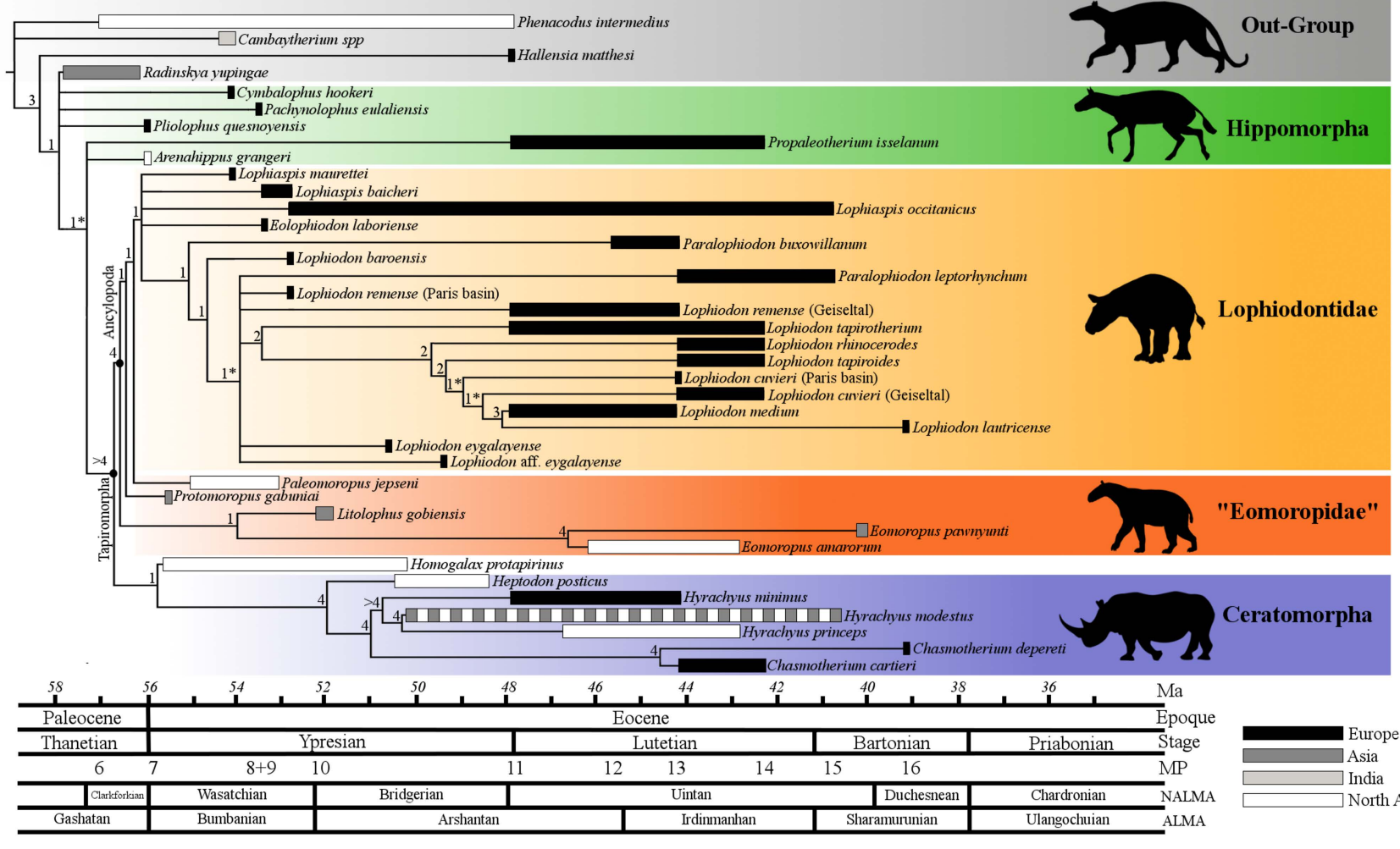

